\title{
Uniaxial Tensile and Simple Shear Behavior of Resistance Spot-Welded Dual-Phase Steel Joints
}

Hong Tao, Wei Tong, Louis G. Hector Jr., and Pablo D. Zavattieri

\author{
(Submitted February 1, 2007; in revised form August 17, 2007)
}

\begin{abstract}
Small test coupons were machined from single spot welds in a dual-phase steel (DP600) to investigate deformation and failure of weld joints in both tension and shear. Quasi-static $\left(\dot{\varepsilon} \sim 10^{-4} 1 / \mathrm{s}\right)$ testing was conducted in a miniature tensile stage with a custom image acquisition system. Strain accumulation in each weld was analyzed where fracture occurred, which was typically outside the fusion zone. A few shear test coupons that failed in the fusion zone were found to have the same spheroidal defects noted in previous work, and thus, severely limited weld strength and ductility. A novel strain mapping method based upon digital image correlation was employed to generate two-dimensional deformation maps, from which local stress-strain curves to failure were computed. As an important first step toward incorporation of material models into weld simulations, a preliminary finite element analysis of a tension test successfully reproduced the experimental results with material models for the base, heat-affected, and fusion zone materials generated from prior work.
\end{abstract}

Keywords automotive, carbon/alloy steels, failure analysis, mechanical testing, welding

\section{Introduction}

The significance of spot welds to automobile structural integrity requires that their deformation and failure properties be carefully understood. An important part of this is the application of suitable experimental methodologies that support the development of deformation and failure laws for the various material zones associated with a spot weld. Dual-phase steel (DPS), which is essentially a low-carbon steel, has attracted the interest of the automotive industry due to its combination of high strength and excellent ductility. The unique mechanical behavior of DPS includes continuous yielding, a low ratio of yield strength to ultimate tensile strength, a high rate of work hardening, and high uniform and total elongation (Ref 1). An example of an experimentally derived failure criterion for large $(216 \mathrm{~mm} \times 38 \mathrm{~mm})$ DPS simple shear coupons with a single spot was recently reported in (Ref 2 ). This criterion relates a critical shear force, at which fracture initiates, to the initial thickness of the spot-welded sheets and the ratio of the maximum hardness to the minimum hardness of the heataffected zone (determined, for example, from indentation tests). If the calculated tensile shear force is greater than the critical value, the weld is predicted to fail by button pullout fracture. Alternatively, if the calculated simple shear force is less than the critical value, then the weld is predicted to fail via the less

Hong Tao, Department of Mechanical Engineering, Yale University, New Haven, CT 06520; Wei Tong, Department of Mechanical Engineering, Southern Methodist University, Dallas, TX 75275; and Louis G. Hector Jr. and Pablo D. Zavattieri, General Motors R\&D Center, Warren, MI 48090-9055. Contact e-mail: wtong@smu.edu.

desirable interfacial fracture mode. However, no attempt was made in (Ref 2) to measure localized strain fields across the weld region and this precluded calculation of local stress fields over the entire weld. In (Ref 3 ), material models (i.e., true axial stress-strain curves to failure) for the three distinct metallurgical zones in a DPS alloy (DP600), i.e., base metal (BM), the heataffected zone (HAZ), and fusion zone (FZ), were generated with a state-of-the-art digital image correlation (DIC) technique. Miniature tensile bars were cut from each zone, and quasi-statically deformed to failure using a tensile substage. For weld FZs with minimal defects, diffuse necking was found to begin at $6 \%$ true strain, and then continue up to $55-80 \%$ true strain. For any given strain, the flow stresses of the weld FZs were found to be at least twice those of the base material, and estimated fracture strains exceeded $100 \%$ for both materials. Only those FZs with substantial defects (e.g., shrinkage voids, cracks, contaminants) failed prematurely, as signaled by their highly irregular strain maps from DIC. Alternatively, the HAZs exhibited a range of complex deformation behaviors, as expected from their microstructural variety. No attempt was made in (Ref 3) to investigate deformation of all three weld zones simultaneously in a single weld.

Characterization of the deformation and failure behavior of a single spot weld (consisting of base, HAZ, and FZ materials) is complicated since the material behavior, the three-dimensional geometry, and the strain path are intertwined. In addition, the strain rates associated with vehicle crash events are often in the $100-1000 \mathrm{~s}^{-1}$ range, which is problematic for some dynamic material testing methodologies. An example of a common (low strain rate) test, wherein geometric effects are strongly coupled with material behavior, is shown in Fig. 1(a): this is a "lapshear" or "tensile-shear" test. This test resulted in a button pullout failure in a single spot weld in simple shear. As material behaviors of the different welds zones cannot be meaningfully extracted from such tests, it is necessary to generate this information in separate tests: this information was generated for low strain rate tests of DP600 and reported in (Ref 3). 
The purpose of the present work was to use the tensile test data from (Ref 3) to quantify the deformation behavior of single DP600 spot welds. Specific goals were: (a) to measure the strain fields in single weld joint coupons in both tension and simple shear tests with DIC; (b) to incorporate the material models for the three material zones reported in (Ref 3 ) in a finite element model of the force-displacement response and local strain distributions of single welds in tension; and (c) to compare the predicted overall deformation behavior and local stress-strain behavior of a contiguous weld with that measured from the miniature test coupons used in (Ref 3). For this purpose, both tension and simple shear coupons were cut from single welds in DP600 and deformed to failure. The strain fields were measured in those regions of each coupon wherein strain localization occurred prior to failure. Two-dimensional strain fields were computed with a strain mapping methodology based upon state-of-the-art DIC. The causes of failure were assessed through examination of fracture surfaces with scanning electron microscopy. The material models generated from tensile test data in (Ref 3) were used in a finite element model of a weld tension coupon to predict the overall force-displacement response and local stress-strain behavior, which were then compared with the measured behavior.

\section{Experimental Procedure}

\subsection{Material}

The dual-phase microstructure resulted from an appropriate combination of heat treatment (unknown) and chemical composition (summarized in Table 1) (Ref 4). As in other DPSs, $\mathrm{Mn}, \mathrm{Cr}$, and $\mathrm{C}$ were the main alloying elements, and their concentrations were comparable to other commercial DPSs (Ref 4). The minimum yield strength (YS) and ultimate tensile strength (UTS) were 300 and $520 \mathrm{MPa}$, respectively (Ref 3). Other DPSs have UTS values of $780,980 \mathrm{MPa}$ (or greater). However, each of these steels, when welded, exhibit comparable microstructural features to DP600. We did not measure the Young's modulus since it is essentially insensitive to steel microstructure.

\subsection{Coupon Preparation and Geometries}

Weld coupons were prepared from sheared, $2.0 \mathrm{~mm}$ thick cold-rolled galvanized sheets. The sheared coupons were $127 \mathrm{~mm}$ long and $38 \mathrm{~mm}$ wide. The resistance spot welds were generated using direct current, single pulse schedules on two identical overlapping coupons. Weld current and weld time were set at $10 \mathrm{kA}$ and 20 cycles (i.e., 1/3 s), respectively. This combination of process parameters was found to consistently generate 7-7.5 mm diameter welds. The resulting geometry, which consisted of five welds in a dual-DPS stack (i.e., two joined sheets), is shown in Fig. 1(b). The tension and shear coupons used in this study were subsequently machined from the larger coupons in the Fig. 1(b) configuration with electrical (a)

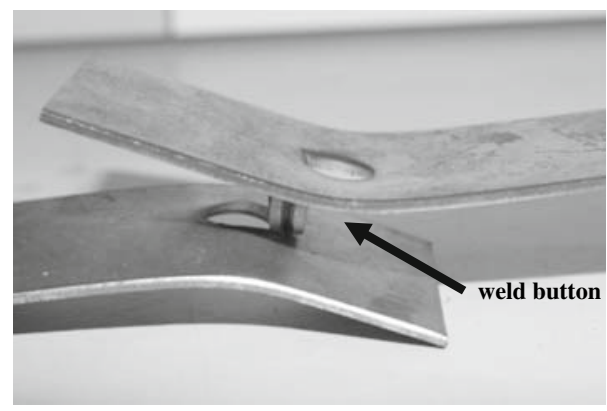

(b)

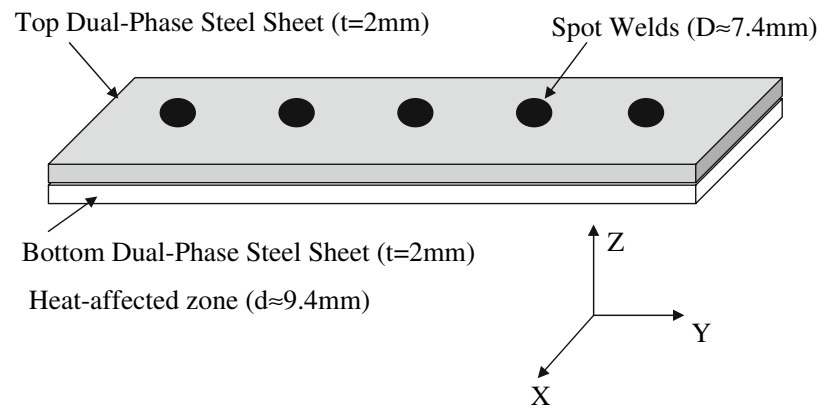

Fig. 1 (a) Lap-shear test coupon (about $38 \mathrm{~mm}$ wide) of a spotwelded DP600 showing button pullout failure. (b) Schematic of resistance spot-welded DP600 stack and the associated coordinate system. The stack is $127 \mathrm{~mm}$ long, $38 \mathrm{~mm}$ wide, and $4 \mathrm{~mm}$ thick

discharge machining (EDM). The EDM geometry followed the patterns shown in Figs. 2 and 3. Figure 2(a) is a top-down view of the coupon sections machined from an individual weld in Fig. 1(b). Since we were specifically interested in the deformation behavior of the welds as a function of the amount of each of the three materials (i.e., base, HAZ, and fusion) in our test coupons, several coupon configurations were generated by carefully controlling the locations along each weld where the coupons were cut with EDM, as indicated in Fig. 2(a). Note that each line in Fig. 2 designates the centerline of each coupon, with the weld center at the center of the large black circle, which represents a spot-weld FZ of about $7.4 \mathrm{~mm}$ in diameter. Ten coupons (including those cut from the base material outside the weld zone) were machined from each weld by staggering the EDM cuts from left-to-right across each weld at fixed spatial intervals of $1.1 \mathrm{~mm}$. The corresponding coupons were labeled $\mathrm{A}$ through $\mathrm{F}$ to identify where they were cut along the weld. For example, weld coupons B, C, and D were cut at distances of $1.1,2.2$, and $3.3 \mathrm{~mm}$ from the weld center, while coupon $\mathrm{E}$ was cut at a distance of $4.4 \mathrm{~mm}$ from the center of the weld so as to include only the HAZ material (white annular region surrounding the black weld zone). Coupon $\mathrm{F}$ was cut at a distance of $5.5 \mathrm{~mm}$ from the center of the weld to consist entirely of base material. With a spot weld of $7.4 \mathrm{~mm}$ in diameter, and the HAZ about $1.0 \mathrm{~mm}$ thick, typical lengths of the weld zone material were $7.4,7.06,5.95$, and $3.35 \mathrm{~mm}$, for

Table 1 Nominal chemical composition of the dual-phase steel used in the present work (in wt.\%, balance Fe)

\begin{tabular}{cccccccccccccc}
\hline $\mathbf{C}$ & $\mathbf{M n}$ & $\mathbf{C r}$ & $\mathbf{M o}$ & $\mathbf{N i}$ & $\mathbf{T i}$ & $\mathbf{V}$ & $\mathbf{A l}$ & $\mathbf{S i}$ & $\mathbf{P}$ & $\mathbf{S}$ & $\mathbf{B}$ & $\mathbf{N}$ & $\mathbf{O}$ \\
\hline 0.11 & 1.5 & 0.27 & $<0.005$ & 0.02 & $<0.005$ & 0.06 & 0.06 & 0.1 & 0.02 & $<0.003$ & $<0.001$ & 0.007 & 0.0028
\end{tabular}



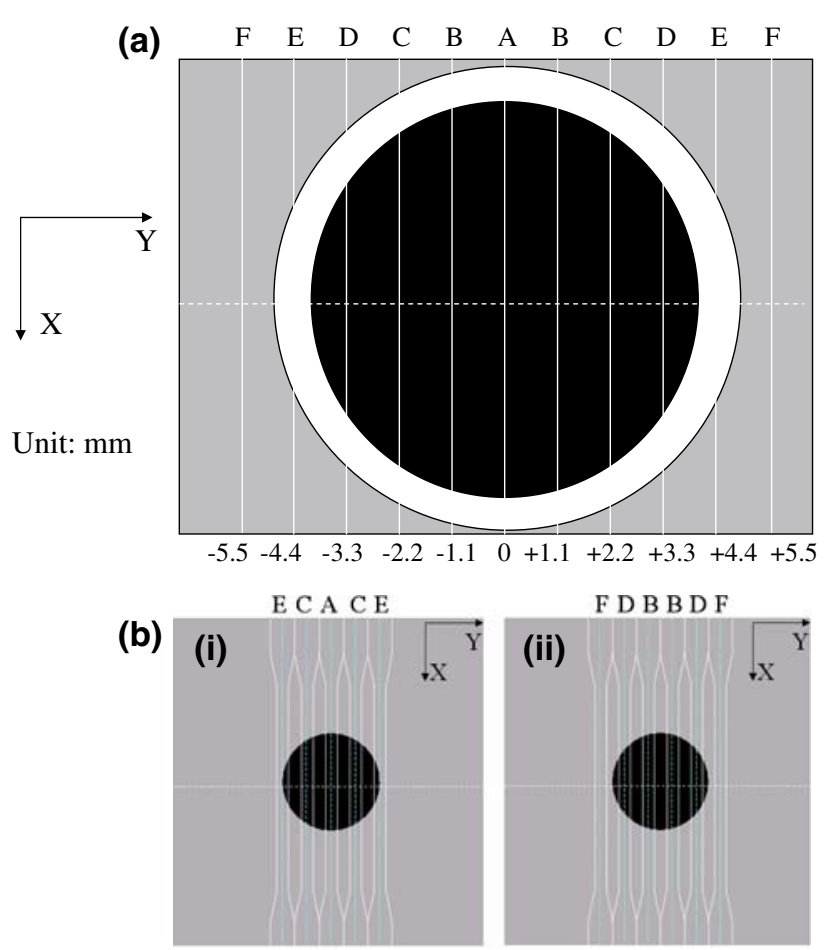

E C A C E

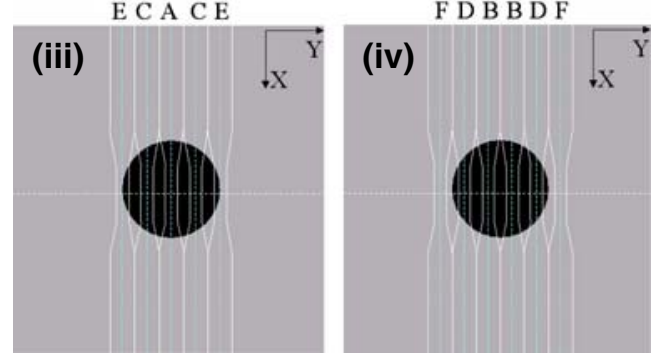

Fig. 2 (a) Schematic designation of different tensile and shear coupons A-F in terms of the locations of their center lines (marked by solid white straight lines) with respect to the center of an individual weld. The sold black circle designates the weld, and its outer white ring designates the heat-affected zone (HAZ). (b) Schematics of different tensile coupon gage section geometries relative to resistance spot-welded DPS stack. Black circle covers the spot weld and part of the HAZ. The length of the gage section is (i-ii) $12 \mathrm{~mm}$; (iii-iv) $3 \mathrm{~mm}$

types A, B, C, and D test coupons, respectively, each with a $12 \mathrm{~mm}$ gage length. The corresponding lengths of the HAZ material at both ends of the weld zone were 1.00, 1.04, 1.18, and $1.67 \mathrm{~mm}$, for types A, B, C, and D coupons, respectively. The length of the HAZ material was $3.3 \mathrm{~mm}$ at the center for the type E test coupons (with no weld zone at all).

The schematics in Fig. 2(b) show the entire coupon geometry through the spot-weld stack (these are a de-magnified views of Fig. 2a). Figure 2(b-i) and 2(b-ii) show coupons that were machined with a $12 \mathrm{~mm}$ gage section. Five coupons were machined from each weld by staggering the EDM cuts from left-to-right across each weld at fixed spatial intervals. The corresponding coupons are labeled A through $\mathrm{F}$ to identify where, along the weld, they were cut. In Fig. 2(b-i), for example, $12 \mathrm{~mm}$ coupon "A" was cut through the center of a weld, whereas its counterpart "B" in Fig. 2(b-ii) was cut to the left and right of the center of another weld. Weld coupons B and $\mathrm{C}$ were cut at greater distances from the weld center, while coupon $\mathrm{E}$ was cut so as to include both $\mathrm{FZ}$ and $\mathrm{HAZ}$ materials. Coupon $\mathrm{F}$ was cut in the base material and contained no material from the weld HAZ since no weld zone was present. Figure 2(b-iii) and 2(b-iv) show coupons cut with $3 \mathrm{~mm}$ gage sections. For each of these subsequent gage sections, the cuts were staggered so as to generate varying amounts of FZ, HAZ, and base material, as previously described. Unlike the miniature coupons considered in (Ref 3 ), each of which was machined from one of the three weld zones, the coupons in Fig. 2(b) were designed to contain variable amounts of each of the three weld zone materials so as to enable study of both material and geometric effects which are coupled in practical application. Note that coupons with $6 \mathrm{~mm}$ gage sections (not shown in Fig. 2) were machined for the simple shear tests at the locations $\mathrm{A}, \mathrm{B}$, and $\mathrm{C}$.

Figure 3 shows schematics of side views (i.e., looking in the $\mathrm{XY}$ plane perpendicular to the weld axis $\mathrm{Z}$ in Fig. 2) of tensile (Fig. 3a, c) and simple shear (Fig. 3b, d) coupons cut from position A (shown in Fig. 2b-i and 2b-iii). All coupons (except those fabricated from the base material only) consisted of two steel sheets each with a $2 \mathrm{~mm}$ thickness. The gage section lengths were $12 \mathrm{~mm}$ (Fig. 3a and $3 \mathrm{~b}$ ) and $3 \mathrm{~mm}$ (Fig. 3c and $3 \mathrm{~d}$ ). Choice of the three gage section lengths enabled study of the effects of different amounts of each of the three weld materials in the coupon gage lengths. For example, Fig. 3(a) shows that the $12 \mathrm{~mm}$ gage section included all three materials, i.e., base, HAZ, and FZ (cf. " $A$ " in Fig. 2a and 2b). This is indicated by the location of the interfacial separations (denoted by arrows in Fig. 3a between the top and bottom coupons within the gage section). The interfacial separations in Fig. 3(c) and 3(d) for the $3 \mathrm{~mm}$ gage section do not penetrate the weld $\mathrm{FZ}$, and the gage section, therefore, consisted entirely of weld FZ material. Note that the simple shear coupons were machined as tensile coupons with the material removed from the top and bottom sheets, to obtain the geometry shown in Fig. 3(b) and 3(d). Similar coupon geometries were machined from the remaining locations in Fig. 2 (although not all of these were tested). Figure $3 \mathrm{e}$ is a schematic of the tensile-shear test showing the weld (or shear) region of length $L$ and width $W$ (shaded area), $F$ is the applied load, and $T$ is the sheet thickness. Hence, the shearing area is $W L$, and the smallest area perpendicular to the applied load is WT. Figure 3(f) is a photomicrograph showing a cross section with the three material types in a typical DP600 spot weld (BM = base material, HAZ = heat-affected zone, FZ = fusion zone). Note that individual tensile coupons are referred to with a " $\mathrm{T}$ " prefix, whereas the shear coupons carry the "S" prefix, as indicated in the Fig. 3 caption.

Prior to tensile testing, the surfaces of each coupon were examined for preexisting cracks and machining irregularities: none was noted on any of the coupons. Following this, the coupons were then decorated with black and white patterns on one surface in the $\mathrm{XZ}$ plane to enhance image contrast for the image acquisition and correlation process. A thin layer of white paint droplets was first sprayed onto the surface. Once this layer dried, it was then lightly decorated with a layer of black paint droplets forming random black and white patterns.

\subsection{Testing Procedure}

The uniaxial tensile and simple shear tests were conducted in a miniature tensile tester (see Fig. 4) with a $50 \mathrm{~mm}$ total travel and 4400-N load capacity (Ref 3 ). The time history was 


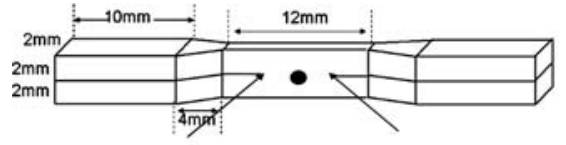

(a)

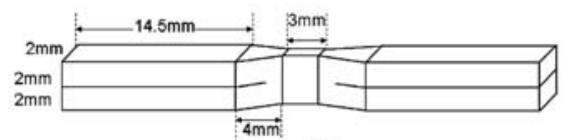

(c)

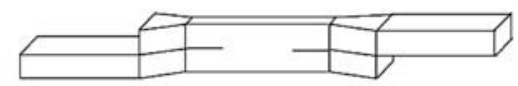

(b)

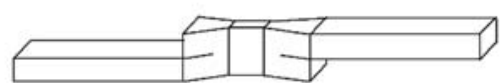

(d)

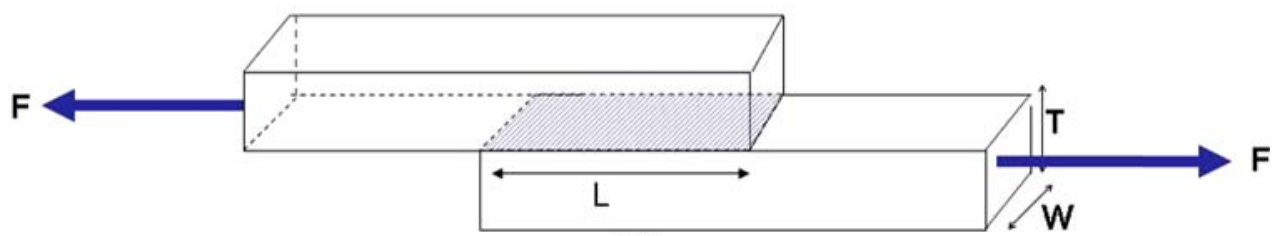

(e)

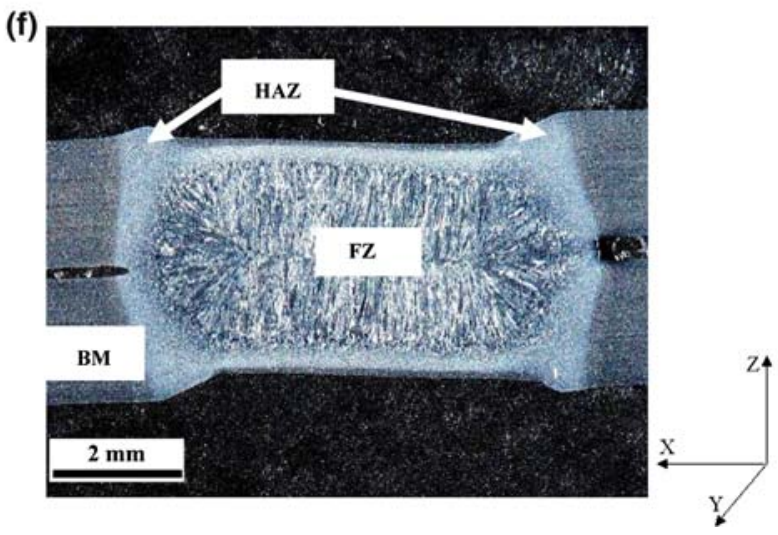

Fig. 3 Tensile (a, c) and shear (b, d) specimens cut from location A (as shown in Fig. 2) with a nominal gage section of 4 mm width (along the Z-axis) and $0.5 \mathrm{~mm}$ thick (along the Y-axis): The length of the gage section along the X-axis is (a-b) $12 \mathrm{~mm}$ (TA12 and SA12 coupons (c-d) $3 \mathrm{~mm}$ (TA3 and SA3 coupons)). Arrows in (a) denote the interfacial separation or gap between the two welded steel plates. The black dot in (a) represents the image surface on each coupon. Schematic (e) pertains to quantities in Eq 2. The shaded area $W \times L$ is the shearing region. The photomicrograph in (f) shows a cross section through a typical DP600 spot weld with the three different material zones $(\mathrm{BM}=$ base metal, $\mathrm{HAZ}=$ heat-affect zone, $\mathrm{FZ}$ = fusion zone)

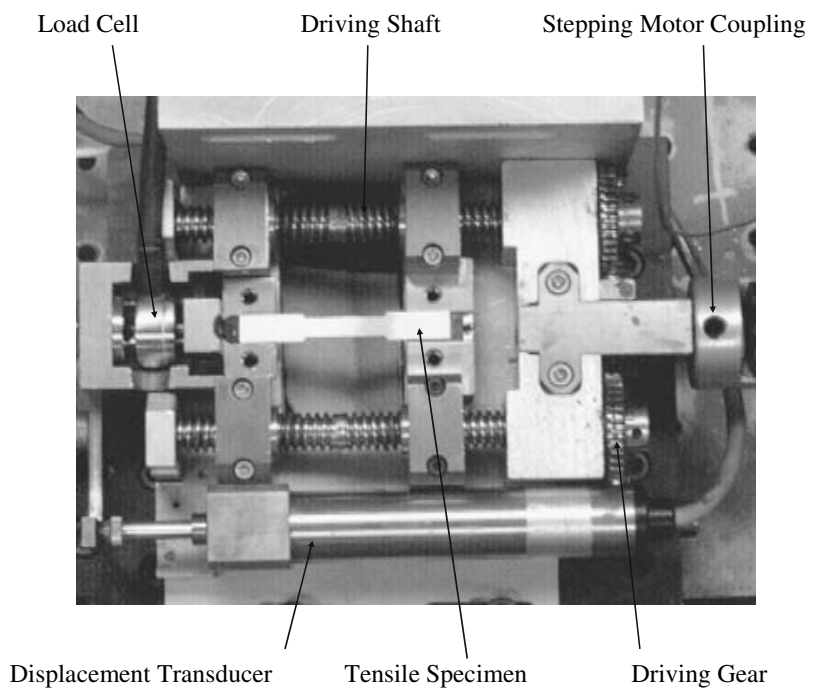

Fig. 4 A top view of the desktop miniature tensile tester mounted with a sheet metal test coupon logged in a computer by tracking the stepping number of the stepping motor, and associating recorded axial load and displacement of the tensile testing apparatus with a given stepping number. All data were recorded at a sampling rate of $8 \mathrm{~Hz}$. The strain rate for the tensile tests was in the $2.25-$ $3.67 \times 10^{-4} \mathrm{~s}^{-1}$ range, while that for the simple shear tests fell in the $2.76-3.45 \times 10^{-4} \mathrm{~s}^{-1}$ range (each test was a constant crosshead displacement rate test). The higher strain rate in the shear tests was due to a shorter gage section length of the shear test coupons.

During the tests, images were captured from one surface of the gage section of each coupon in the XZ plane (i.e., with normal aligned with the Y-axis, see Figs. 2 and 3). The specific surface that was imaged is denoted by a superimposed black dot in the Fig. 3(a) geometry. For this purpose, an off-the-shelf $\mathrm{B} / \mathrm{W}$ CCD camera was aligned with the Y-axis and directed to capture images at an interval of every $36 \mathrm{~s}$ in each test. Each grayscale digital image was 640 -by-480 pixels with a spatial resolution of $3.3 \mu \mathrm{m} /$ pixel. Also used were Canon digital cameras (Model EOS Rebel with 6.3 MP or model EOS 20D with $8.2 \mathrm{MP}$ ), which enabled image capture at every $8 \mathrm{~s}$ in 
testing of some of the larger coupons: this provided an increased field of view while maintaining a sufficiently fine spatial resolution.

Fracture surfaces were examined using a FEI XL-30 scanning electron microscope (SEM) to investigate the fracture mechanism and the potential presence of subsurface defects (the latter are, in principle, detectable by the surface deformation maps generated from DIC, see Ref 3). To provide an estimate of the true strain at final failure, the cross-sectional area of the projected fracture surface of each tensile coupon was measured using secondary electron images.

\subsection{Digital Image Correlation and Instrumentation}

Since application of extensometers or electromechanical strain gages for measurement of strain fields in the coupons shown in Fig. 3 was impractical (due to the small size of each coupon), an alternative methodology was required. The DIC technique, which computes displacements and strains at points in a digital grid that deforms with changes in digital images recorded from the coupon surface, was found to be ideal for this application. Recently, the DIC technique has been used to measure whole-field surface displacements and strains over a broad range of length scales (Ref $3,5-15)$. Its applicability and benefits have been demonstrated in a diverse range of studies, which include measurement of individual grain deformation in metal alloys (Ref 10), the quantification of deformation bands in Al alloys (i.e., the so-called PLC effect) (Ref 7, 8, 12), and crack propagation in NiTi shape memory alloys (Ref 9, 11). One of the main advantages of the DIC methodology is that it provides very accurate local strain measurements beyond diffuse necking (diffuse necking is the point when a peak load is reached, which typically marks the limit of conventional uniaxial tension test methodology using extensometers). This enables measurement of true stress-strain behavior of a material up to localized necking (Ref 3). If the sampling rate of the image acquisition system is high enough, it is possible to capture strain in the material very close to the fracture point. Displacement fields are extracted from comparisons between contrast features in pairs of digital images before and after the application of a strain increment. More specifically, the physical problem of measuring in-plane displacements at a point in a digitally superimposed grid (i.e., the digital strain gage) on a macroscopically flat surface is formulated in terms of minimization of a correlation function over a subset image region containing the grid point with respect to six deformation mapping parameters (the two displacement components and their four spatial gradients). These parameters, which are constant for each subset region, include two in-plane displacement parameters, $u(x, y), v(x, y)$, and their four spatial derivatives, viz., $u_{x}(x, y), u_{y}(x, y), v_{x}(x, y)$, and $v_{y}(x, y)$, where the subscripts denote differentiation with respect to the corresponding spatial coordinate. These vary spatially from grid point to grid point, and hence form the two-dimensional whole field displacement and strain maps, which can be reported cumulatively (i.e., comparison of an image prior to loading with that at a given loading level) or incrementally (i.e., comparison of images between consecutive loading steps).

The process of computing the whole field displacement and strain maps involves two steps. In the first step, images of one surface of the coupon are recorded at prescribed intervals during the deformation process, reduced to grayscale, and then saved as raw data files of brightness values. In the second step, the region of interest in the digital images is then defined with a set of grid points (similar to nodes in a finite element mesh) that lie at the center of user-specified subset arrays (or small area elements) within each image. The six mapping parameters are computed at each grid point. Additional postprocessing filtering and smoothing is then used to compute the translation, rotations, extension, and shear of each subset. The in-plane true strain components, $\varepsilon_{1}, \varepsilon_{2}$, and $\varepsilon_{12}$ at each load step are then computed incrementally from a consecutive set of digital images. The DIC software used in the present work was SDMAP-3D, which was developed by Tong et al. (Ref 5-10). The software is implemented with features for correcting nonsquare pixels and lens distortion of the imaging system so small strains can be accurately detected (such corrections were unnecessary for the plastic strain levels measured in this study).

\subsection{Extraction of True Stress-Strain Curves from Two-Dimensional Strain Maps}

It was assumed that each coupon undergoes planar rigid body motion and deformation, and that its surface remains flat. In addition, the surface contrast features (i.e., the applied black and white paint droplets) are assumed to be stable throughout the deformation process (no evidence from any of the tests suggested otherwise). The principle of DIC is to correlate the local contrast patterns by finding an optimum 2D displacement field. The matching between the images before (reference) and after (current) deformation is characterized by a normalized least-squared difference correlation coefficient, as described in (Ref 5). The strain field is then obtained through strain-displacement relations from continuum mechanics. True stress in tension is computed from the force equilibrium equation using the strain measurements via the following relationship:

$\bar{\sigma}_{1}=\frac{F e^{\bar{\varepsilon}_{1}}}{W T}$

where $F$ is the total axial load, $W$ and $T$ are the initial width and thickness, respectively, of the rectangular tensile coupon, $\bar{\varepsilon}_{1}$ is the average axial true strain measured by the DIC technique, and $\bar{\sigma}_{1}$ is the average axial true stress. The axial strain $\bar{\varepsilon}_{1}$ is averaged using one of the four different strain measures listed in Appendix A. According to a previous evaluation (Ref 13), $\bar{\varepsilon}_{1}^{(3)}$ was found to be the most accurate strain measure for calculation of $\bar{\sigma}_{1}$ in Eq 1. The average shear stress $\tau(\bar{\gamma})$ in the simple shear tests was computed through the following force equilibrium equation:

$\tau(\bar{\gamma})=\frac{F}{W L}$.

Note that $\bar{\gamma}$ is the average shear strain measured by the DIC technique since $\bar{\gamma}=2 \bar{\varepsilon}_{12}=2 \bar{\varepsilon}_{x z}$. Note that we use $1=x$, $2=y$, and $3=z$ interchangeably throughout. The remaining symbols are defined in Fig. 3(e). The shear strain $\bar{\gamma}$ is averaged along the shearing zone across the whole gage section area $(W L)$ of a simple shear coupon. When the stress state within the measurement zone of the test coupon can be approximated to uniaxial tension or simple shear, the average true stress-true strain curves in tension or shear can then be regarded to be effective true stress-true strain curves. 


\section{Experimental Results and Discussion}

\subsection{Tensile Tests}

Table 2(a) lists the measured initial yield strength (at the $0.2 \%$ offset strain), true axial strain at the maximum load point, true strain, true stress, and load just prior to the major drop in load following strain localization. The average and peak true strain values just prior to the major drop in stress reported in Table 2(a) were computed using Eq A3 and A4, respectively. The major drop in stress is the apparent drop in true stress, or point at which the stress-strain curve has a negative slope, and is indicative of failure. Tensile true stress just prior to its major drop was computed from Eq 1 using peak true strain values based on Eq A4. The test coupons were designated by two uppercase letters, followed by a number indicating the gage length (e.g., 3 or $12 \mathrm{~mm}$ ), and ending with a lower caser letter (in addition to the test prefix GMT\#). The first uppercase letter is either $\mathrm{T}$ (tensile) or S (shear), and the second uppercase letter is A-F, indicating the location of the test coupon cut from the spot weld (see Figs. 2a and 2b). Hence, the two uppercase letters and number designate the type of test coupon, while the lowercase letter at the end identifies the specific test for the associated coupon type. For example, test coupon TC12a was a tensile test coupon with a gage length of $12 \mathrm{~mm}$, cut from spot weld location C (2.2 mm from the center-see Fig. 2), and it is the first in a sequence of tests on this coupon geometry, as indicated by "a."

Of immediate interest is the observation that there is little difference in the initial yield strengths of TA3b (1148.9 MPa), TB3b (1154.7 MPa), and TC3c (1151.4 MPa). The same is true when comparing the axial stresses prior to the major stress drop in all three coupons $(1752,1779$, and $1742 \mathrm{MPa})$. The true axial strain prior to the major drop in stress was greatest for TC3c (29.6\%) indicating that the greatest ductility was achieved for this coupon. The purpose of the coupon types $\mathrm{TA} 3 \mathrm{~b}, \mathrm{~TB} 3 \mathrm{~b}$, and TC3c was to explore possible variations in the measured mechanical properties of only the $\mathrm{FZ}$ material by sampling material within the FZ moving from its center to its periphery. Clearly, the ductility of the FZ material in terms of the average strain prior to necking failure is not constant, but rather, decreases with position moving from the edge $(29.6 \%)$ to the center $(16.1 \%)$ of the FZ. Out of those coupons with the $12 \mathrm{~mm}$ gage length, TA12a (cut from the center of the weld) failed at the greatest stress $(1291 \mathrm{MPa})$, but its local strain prior to failure $(53.4 \%)$ was slightly greater than that of TF12b (51.4\%), which was taken entirely from the base material, and slightly less than TB12a (54.2\%), which had more HAZ material (see Fig. 2). The same observation holds for the true strain at the UTS. Although the difference in coupon geometries precludes a meaningful quantitative comparison of the measured quantities, it is interesting to note that the strain levels prior to failure are (on average) greater for those weld coupons with the $12 \mathrm{~mm}$ gage length than those for the $3 \mathrm{~mm}$ gage length. The $12 \mathrm{~mm}$ coupons incorporate each of the three major weld material types (i.e., base, HAZ and fusion-see Fig. 3).

Figures 5-13 show digital images of selected tensile coupons that were successfully loaded in the stage along with the associated axial strain contour maps just prior to failure. Note that the superimposed blue box in each grayscale digital image denotes the region of the associated digital grid (or strain gage), within which DIC processing was executed. The size of each grid (listed beneath each color contour map) was such that it enclosed the region of the coupon that ultimately failed. The corresponding axial strain contour maps (e.g., Fig. 5b) have a one-to-one area correspondence with the digital grid region. As originally machined, coupons TA3a, TB3a, and TC3a (with a gage length of $3 \mathrm{~mm}$ ), all failed outside their fusions zones since their gage sections consisted entirely of the very strong FZ material (see Figs. 2 and 3). The three tensile coupons $\mathrm{TA} 3 \mathrm{~b}, \mathrm{~TB} 3 \mathrm{~b}$, and TC3c were subsequently modified (with further EDM) to have a tapered gage section in the $\mathrm{XZ}$ plane (see Figs. 5a, 6a, and 7a): this modification was sufficient to induce failure inside the gage section.

The axial strain contour maps in Figs. $5 \mathrm{~b}, 6 \mathrm{~b}$, and $7 \mathrm{~b}$ show strain localization. This is denoted by the contour bands (red,

Table 2 Summary of results on (a) tensile test coupons and (b) simple shear test coupons

(a)

\begin{tabular}{lcccc}
\hline $\begin{array}{l}\text { Coupon name } \\
\text { (Test number) }\end{array}$ & $\begin{array}{c}\text { Axial yield } \\
\text { stress, MPa }\end{array}$ & $\begin{array}{c}\text { True strain at the ultimate } \\
\text { tensile strength } \\
\text { (Max. load point) }\end{array}$ & $\begin{array}{c}\text { Average \& peak true } \\
\text { axial strain prior to } \\
\text { major stress drop }\end{array}$ & $\begin{array}{c}\text { Stress, MPa, and Load, } \\
\text { N prior to major stress drop }\end{array}$ \\
\hline TA3b (GMT\#154) & 1148.9 & 0.073 & $0.161 / 0.323$ & $1752 / 312.6$ \\
TB3b (GMT\#155) & 1154.7 & 0.035 & $0.228 / 0.602$ & $1779 / 288.7$ \\
TC3c (GMT\#157) & 1151.4 & 0.075 & $0.296 / 0.296$ & $1742 / 661.9$ \\
TF12b (GMT\#177) & 383.8 & 0.149 & $0.514 / 0.732$ & $1170 / 143.0$ \\
TA12a (GMT\#178) & 462.1 & 0.159 & $0.534 / 0.650$ & $1291 / 1047.4$ \\
TB12a (GMT\#179) & 407.9 & 0.164 & $0.542 / 0.650$ & $1288 / 897.2$ \\
TC12a (GMT\#180) & 350.1 & 0.146 & $0.442 / 0.674$ & $1080 / 497.2$ \\
TD12b (GMT\#181) & 376.2 & 0.100 & $0.462 / 0.595$ & $1266 / 730.8$ \\
TE12b (GMT\#182) & 400.9 & 0.129 & $0.434 / 0.562$ & $1131 / 500.7$ \\
\hline
\end{tabular}

(b)

\begin{tabular}{lcccc}
\hline $\begin{array}{l}\text { Coupon name } \\
\text { (Test number) }\end{array}$ & $\begin{array}{c}\text { Shear yield } \\
\text { stress, MPa }\end{array}$ & $\begin{array}{c}\text { Shear strain at the } \\
\text { maximum shear strength }\end{array}$ & $\begin{array}{c}\text { Peak shear strain } \\
\text { (Prior to major stress drop) }\end{array}$ & $\begin{array}{c}\text { Stress, MPa, and Load, N, } \\
\text { prior to major stress drop }\end{array}$ \\
\hline SC6a (GMT\#143) & 245.7 & 0.007 & 0.0144 & $502 / 343.5$ \\
SA12a (GMT\#145) & 194.0 & 0.065 & 0.121 & $470 / 362.5$ \\
SA12b (GMT\#151) & 223.4 & 0.068 & 0.278 & $422 / 352.7$ \\
\hline
\end{tabular}




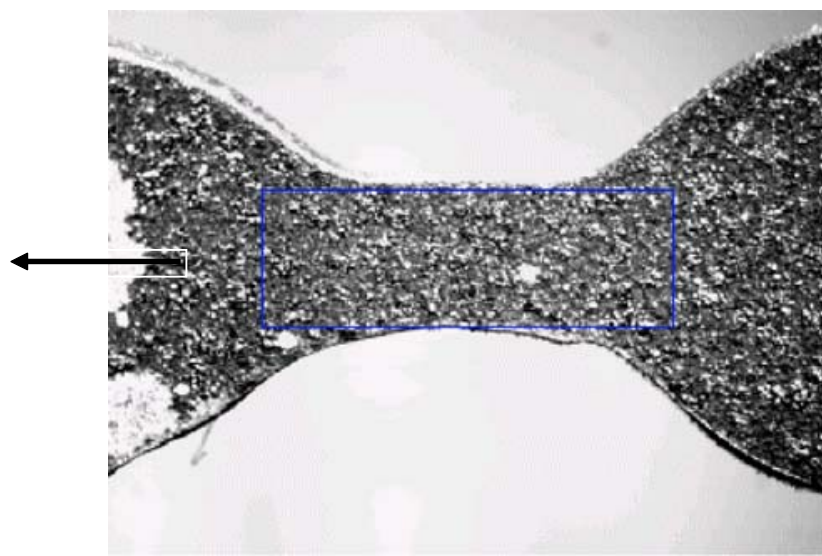

(a) Force right before failure: $312.57 \mathrm{~N}$. The blue DIC box dimensions are $3.39 \mathrm{~mm} \times 1.13$ $\mathrm{mm}$.

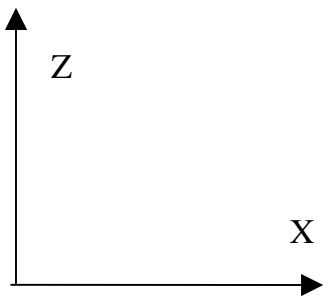

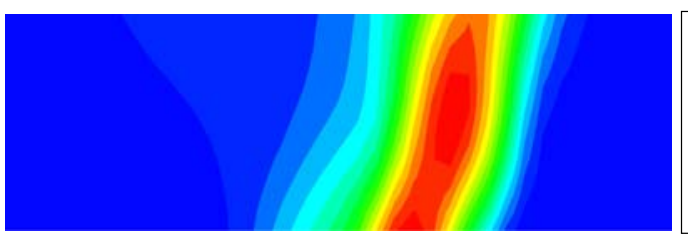

(b) The field of view is $3.39 \mathrm{~mm} \times 1.13 \mathrm{~mm}$

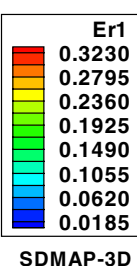

SDMAP-3D

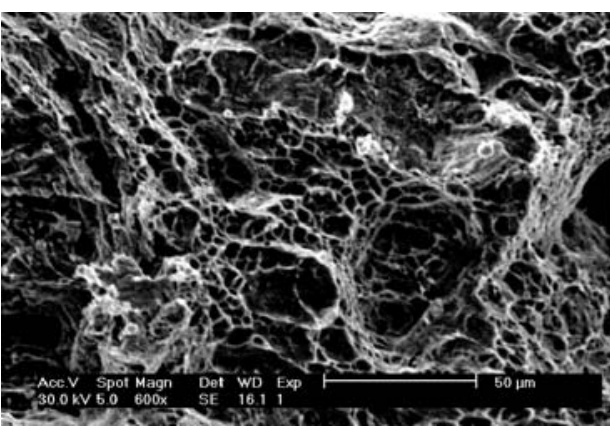

(c) $600 \mathrm{x}$

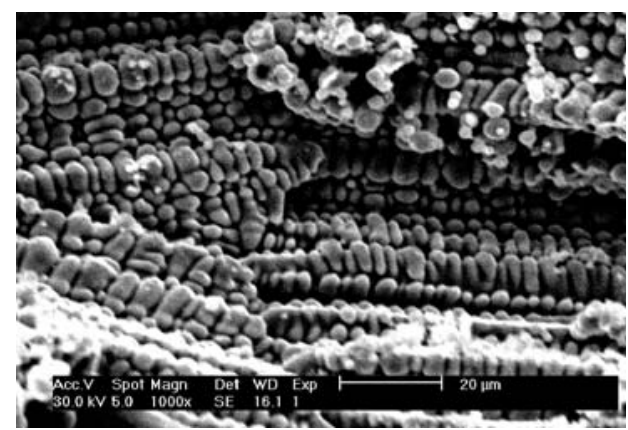

(d) $1000 \mathrm{X}$

Fig. 5 (a) Digital image of modified tensile coupon TA3b (GMT\#154). Blue box shows the digital grid region used for DIC. The arrows denote the tensile axis. (b) Axial strain contour map just prior to failure. (c, d) SEM images of one fracture surface showing microstructural features

orange, yellow) surrounded by regions of low strain in deep blue. The peak local tensile strain in test TB3b (i.e., $60.2 \%$ in the key to Fig. 6b) was about twice that in TA3b and TC3c (i.e., $32.3 \%$ and $28.6 \%$, in the keys of Figs. $5 \mathrm{~b}$ and $7 \mathrm{~b}$, respectively), but it is also more localized near the top edge of the gage section. The local strain field in test TB3b resembles that due to an asymmetric edge crack (i.e., the peak strain is at the upper edge shown in Fig. 6b instead of following a more symmetric distribution along the neck. The strain maps in Figs. 5b and 7b are more indicative of a typical neck in tension. This discrepancy was resolved through examination of the fracture surfaces of each coupon with SEM. Figures 5(c, d), 6(c, d), and $7(\mathrm{c}, \mathrm{d})$ show representative microstructures in the fracture surfaces from each test. The fracture surface morphologies differed substantially between coupons TA3b, TB3b, and $\mathrm{TC} 3 \mathrm{c}$, indicating that the microstructure varied even within the FZ from point-to-point. The fracture surfaces of coupon
TA3b exhibited the greatest variability in microstructure in that both deep voids, with a nominal $10 \mu \mathrm{m}$ size (see Fig. 5c), signaling ductile-like rupture, and spherical material defects (Fig. 5d) suggesting limited ductility, were noted. The spheroidal defects were also noted in (Ref 3$)$, and were assumed to be the cause of premature fracture of some of the miniature coupons consisting entirely of weld material addressed in (Ref 3). A different fracture surface morphology, consisting of shallow voids (Fig. 6c) and steps (Fig. 6d), was noted on coupon TB3b. The fracture surface of coupon TC3c was suggestive of ductile failure with a fairly uniform distribution of voids having a $6 \mu \mathrm{m}$ nominal size (Fig. 7c, d). It is interesting to note that as the microstructure of TC3c appeared to be the most uniform across regions of both fracture surfaces that were investigated with the SEM, this coupon had the highest average strain prior to failure (i.e., of the coupons with a $3 \mathrm{~mm}$ gage length). 


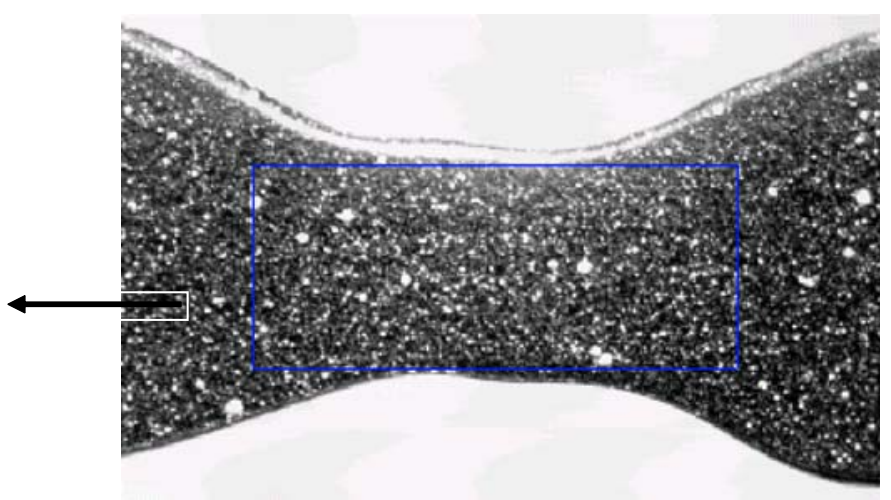

(a) Force right before failure: $288.69 \mathrm{~N}$. The blue DIC box dimensions are $4 \mathrm{~mm} \times 1.7$ $\mathrm{mm}$.
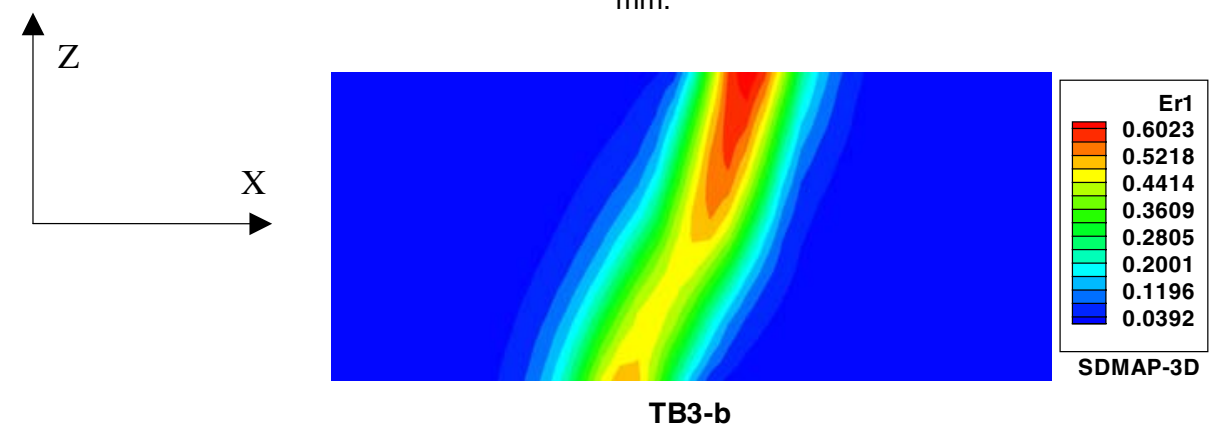

(b) The field of view is $4 \mathrm{~mm} \times 1.7 \mathrm{~mm}$.

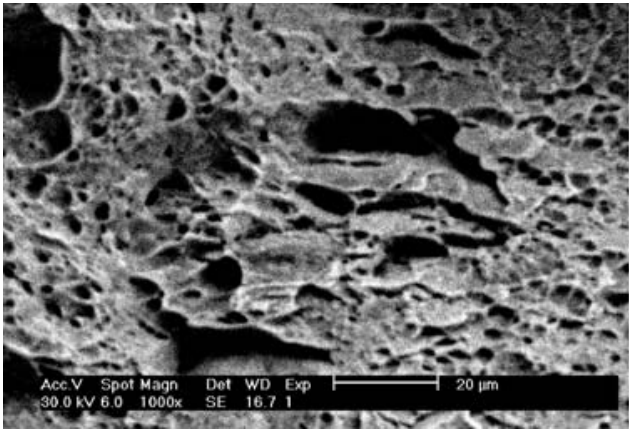

(c) $1000 \mathrm{X}$

Fig. 6 (a) Digital image of modified tensile coupon TB3b (GMT\#155). Blue box shows digital grid region used for DIC. The arrows denote the tensile axis. (Force right before failure: $288.69 \mathrm{~N}$. The blue DIC box dimensions are $4 \mathrm{~mm} \times 1.7 \mathrm{~mm}$.) (b) Axial strain contour map just prior to failure. (The field of view is $4 \mathrm{~mm} \times 1.7 \mathrm{~mm}$.) (c) SEM images of one fracture surface showing microstructural features. $(1000 \times$ )

Figures 8-13 are selected digital images and strain maps of the $12 \mathrm{~mm}$ gage length coupons just prior to failure. For example, a digital image of coupon TA12a along with its strain map just prior to failure are shown in Fig. 8(a) and 8(b), respectively. Note that coupon TA12a consisted of all three materials. The peak strain level achieved prior to failure was $65 \%$ according to the strain map in Fig. 8(b). The strength of material in the gage section was such that failure occurred outside the weld region as indicated by the position of the blue box in Fig. 8(a), within which image correlation was executed. The axial strain distribution was symmetric about the weld up to a strain of $12 \%$. Then strain localization occurred at one side of the coupon outside its gage section (the base metal region). Note that the strain levels in the map of Fig. 9(b) are similar to those in Fig. 8(b), while a higher peak strain level was recorded for TC12a in Fig. 10(b). Figure 11(b) shows that strain localization for TD12a (which consists of all three weld materials, see Fig. 2) occurred outside of the weld zone, which is the center piece connecting the two sheets in Fig. 11(a). Note that the horizontal white line (beneath the blue DIC box) in Fig. 11(a) resulted from light glare, and did not affect the measurement in any way. Coupon TE12b (which was a single sheet coupon consisting of base and HAZ material) and coupon TF $12 b$ (which was a single sheet coupon consisting entirely of base material) failed far off the center of their respective gage sections (see Figs. 12a and 13a respectively). This was due to the fact that their gage sections in the $\mathrm{XZ}$ plane were very long and not tapered across their widths (although all coupons were tapered in the XY plane). According to Figs. 12(b) and 13(b), the peak strain levels in TE12b (with HAZ metal in the middle section of about $3.3 \mathrm{~mm}$ in length) and TF12b (with all base metals) are $56.2 \%$ and $73.2 \%$, respectively. The ruptured 


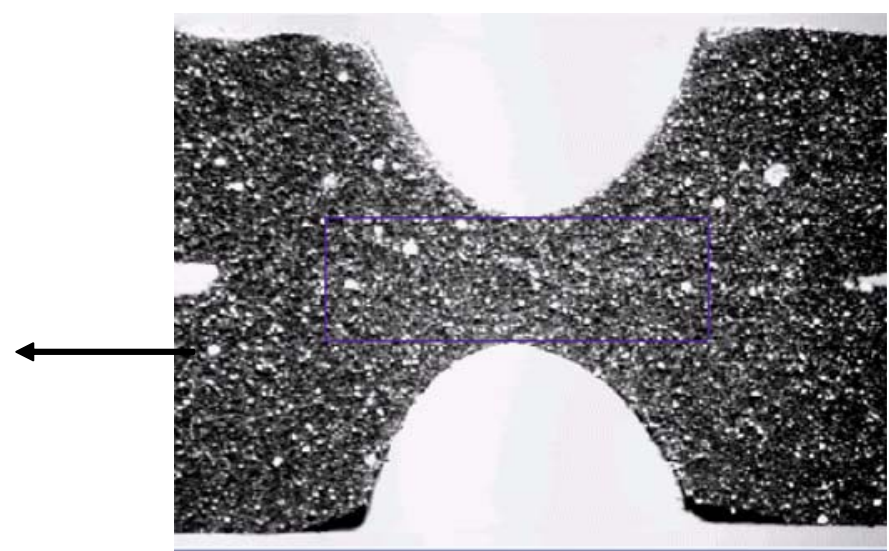

(a) Force right before failure: $661.92 \mathrm{~N}$. The blue DIC box dimensions are $3.06 \mathrm{~mm} \times 0.99$ $\mathrm{mm}$.

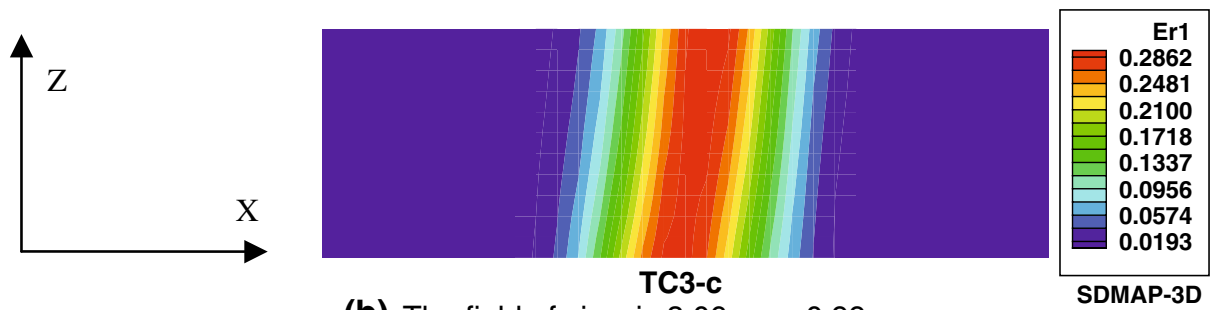

(b) The field of view is $3.06 \mathrm{~mm} \times 0.99 \mathrm{~mm}$.

SDMAP-3D

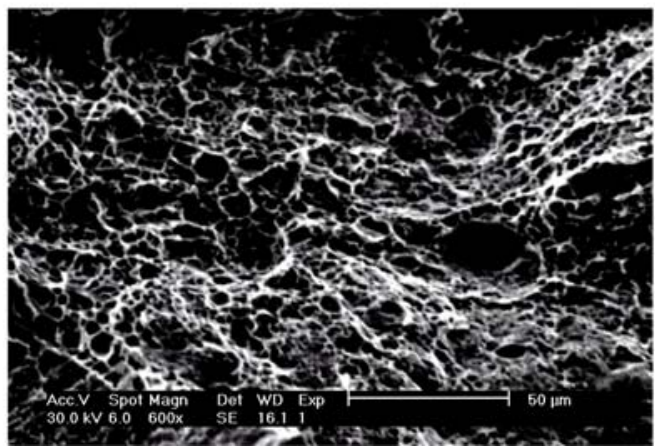

(c) $600 \mathrm{X}$

Fig. 7 (a) Digital image of modified tensile coupon TC3c (GMT\#157). Blue box shows digital grid region used for DIC. The arrows denote the tensile axis. (Force right before failure: $661.92 \mathrm{~N}$. The blue DIC box dimensions are $3.06 \mathrm{~mm} \times 0.99 \mathrm{~mm}$.) (b) Axial strain contour map just prior to failure. (The field of view is $3.06 \mathrm{~mm} \times 0.99 \mathrm{~mm}$.) (c) SEM images of one fracture surface showing microstructural features. $(600 \times)$

surfaces of coupons TA12a and TF12b contained voids with a nominal $4-5 \mu \mathrm{m}$ size (see Figs. $8 \mathrm{c}$ and $13 \mathrm{c}$, respectively). Comparison of the strain maps in Figs. $8 \mathrm{~b}$ and $11 \mathrm{~b}$ for TA12a and TD12b, respectively, show that the maximum strain in the former exceeds that in the latter.

Figure 14 summarizes the material response curves of the different coupons. The material response curves were calculated with Eq 1 using the average strain definition given by Eq A3 in Appendix A. Figure 14 shows that the response curves (true axial flow stresses due to the single material gage section) of tensile coupons TA $3 b$, TB3b, and TC $3 c$ were very similar. The ultimate tensile strength levels of each were close to that of the FZ material GMT\#80 reported in (Ref 3) (1522 MPa, Table 2 in Ref 3), as shown in Fig. 19. The slightly higher stress levels in TA3b, TB3b, and TC3c coupons may be attributed to their short gage lengths. These results are consistent with the fact that each coupon had an all-FZ material gage section (see Fig. 3). Perhaps the most significant difference between the three curves is the maximum strain level, with that for TA $3 \mathrm{~b}$ about $16.1 \%$ and that for TC $3 \mathrm{c}$ about $30 \%$. Figure 14 also shows a set of true axial stress-strain curves of joint coupons with the $12 \mathrm{~mm}$ gage section length. Variations between the stress-strain curves for weld joint coupons (i.e., with weld metal at the center) TA12a, TB12a, $\mathrm{TC} 12 \mathrm{a}$, and TD12b can be attributed to asymmetric necking deformation in the base metal sections of these coupons (see Figs. 8-11). The force-displacement response curves of TE12b and TF12b were also close to one another. The tensile strength of each was close to that of the base metal material reported in (Ref 3) (697 MPa), as shown in Fig. 19. However, TF12b had a slightly higher tensile strength than TE12b.

Note that the true axial strain just prior to the major stress drop in the corresponding stress-strain curves in Table 2(a) differs from the peak strain values in the corresponding strain maps. For example, a $16.1 \%$ true axial strain was measured from TA3b just prior to the major drop in computed axial stress 


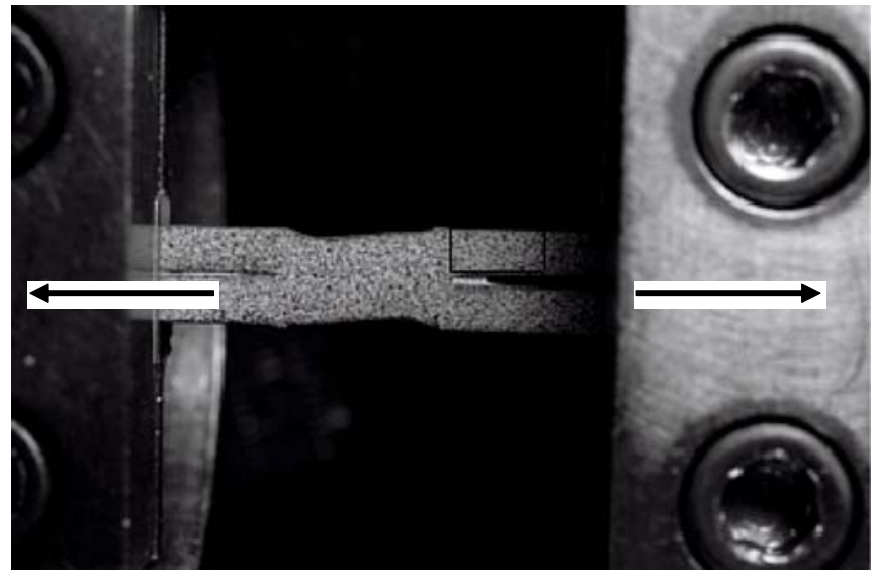

(a) Force right before failure: $1047.36 \mathrm{~N}$. The blue DIC box dimensions are $3.75 \mathrm{~mm} \times 1.68 \mathrm{~mm}$.

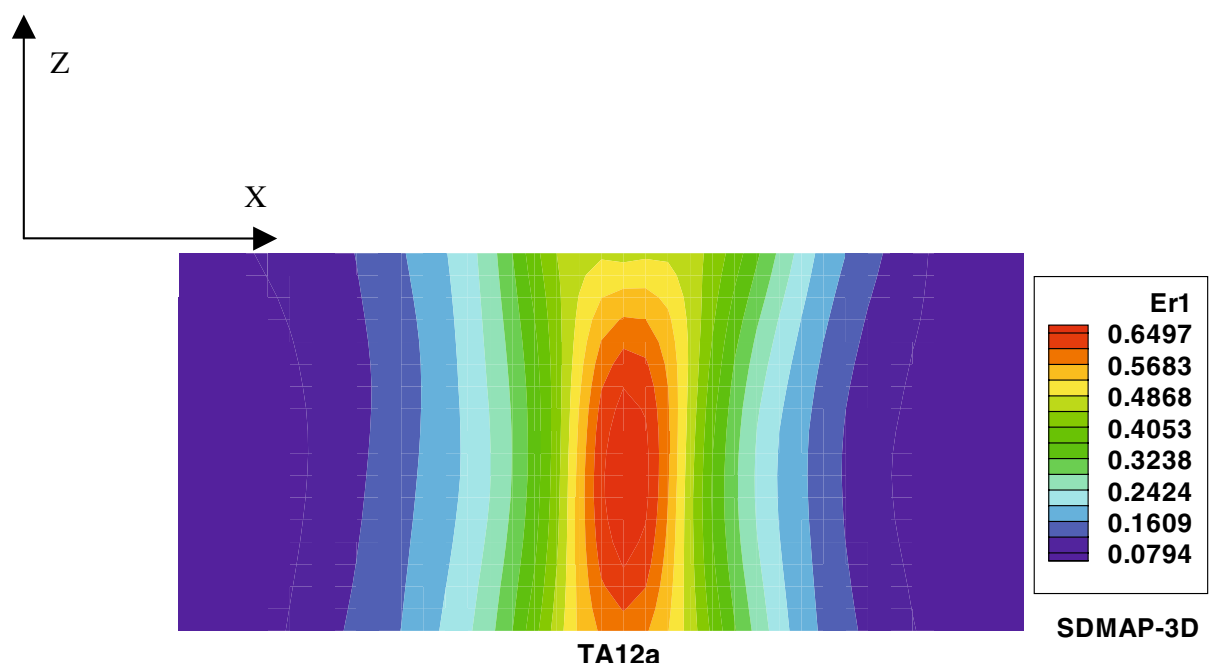

(b) The field of view is $3.75 \mathrm{~mm} \times 1.68 \mathrm{~mm}$.

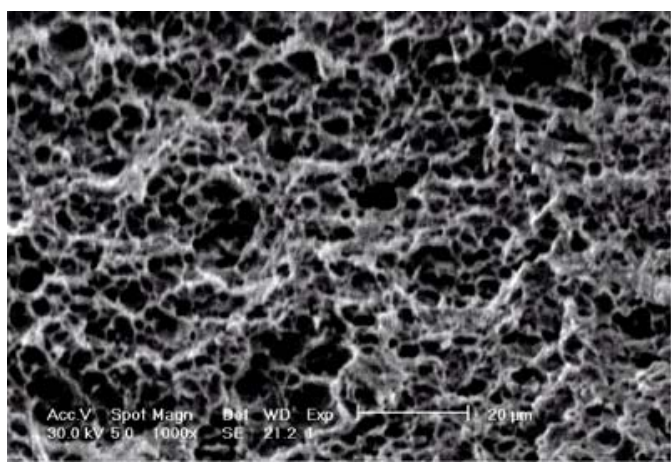

(c) $1000 \mathrm{X}$

Fig. 8 (a) Digital image of tensile coupon TA12a (GMT\#178). Blue box shows digital grid region used for DIC. The arrows denote the tensile axis. (Force right before failure: $1047.36 \mathrm{~N}$. The blue DIC box dimensions are $3.75 \mathrm{~mm} \times 1.68 \mathrm{~mm}$.) (b) Axial strain contour map just prior to failure. (The field of view is $3.75 \mathrm{~mm} \times 1.68 \mathrm{~mm}$.) (c) SEM image of one fracture surface showing microstructural features. (1000×)

(see the curve with the small squares in Fig. 14). However, the peak strain shown in Fig. 5(b) is $32.3 \%$. This is taken from the last image of the coupon just prior to failure. The stress level had already dropped well below the peak stress level in the true stress-true strain curve. Either there was significant (undetectable) damage in the coupon at the stage shown in Fig. 5(b), or the spatial resolution of the strain measurement was insufficient to capture rapid thinning and failure. Similar observations apply for the other coupons.

\subsection{Simple Shear Tests}

A total of 13 simple shear coupons machined from locations A, B, and C (see Figs. 2 and 3) were studied to characterize the 


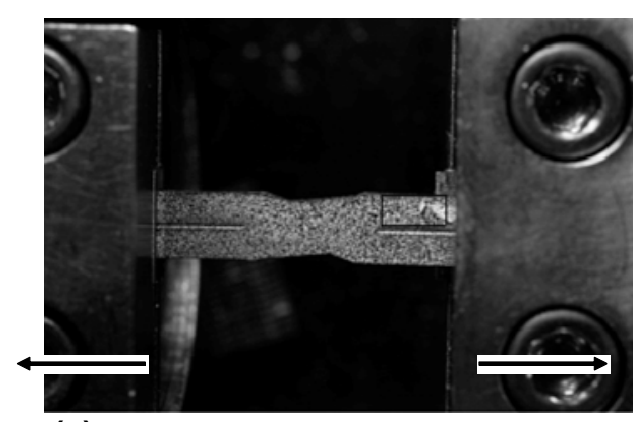

(a) Force right before failure: $897.2 \mathrm{~N}$. The blue DIC box dimensions are $3.79 \mathrm{~mm} \times 1.69 \mathrm{~mm}$.

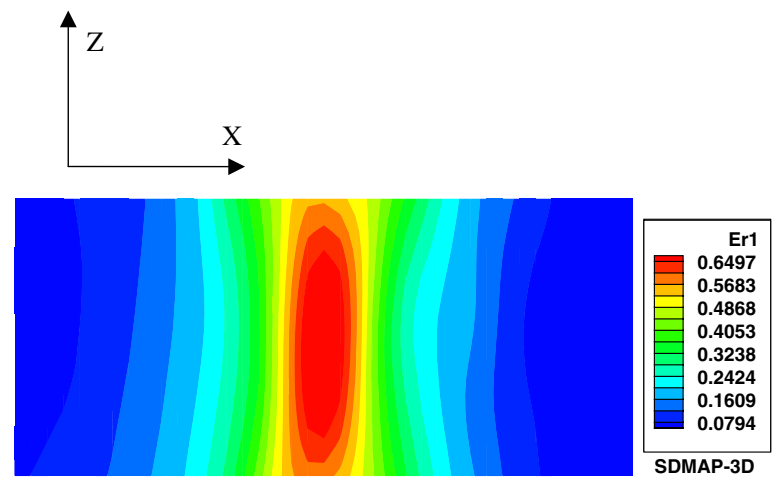

(b) The field of view is $3.79 \mathrm{~mm} \times 1.69 \mathrm{~mm}$.

Fig. 9 (a) Digital image of tensile coupon TB12a (GMT\#179). Blue box shows digital grid region used for DIC. The arrows denote the tensile axis. (Force right before failure: $897.2 \mathrm{~N}$. The blue DIC box dimensions are $3.79 \mathrm{~mm} \times 1.69 \mathrm{~mm}$.) (b) Axial strain contour map just prior to failure. (The field of view is $3.79 \mathrm{~mm} \times 1.69 \mathrm{~mm}$.)

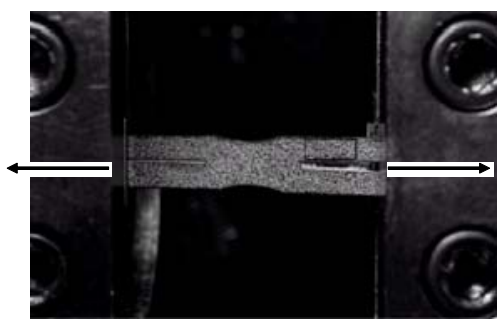

(a) Force right before failure: $497.2 \mathrm{~N}$. The blue DIC box dimensions are $3.8 \mathrm{~mm} \times 1.66 \mathrm{~mm}$.

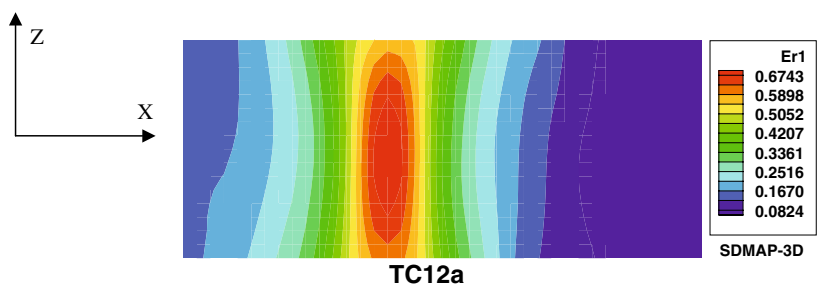

(b) The field of view is $3.8 \mathrm{~mm} \times 1.66 \mathrm{~mm}$.

Fig. 10 (a) Digital image of tensile coupon TC12a (GMT\#180). Blue box shows digital grid region used for DIC. The arrows denote the tensile axis. (Force right before failure: $497.2 \mathrm{~N}$. The blue DIC box dimensions are $3.8 \mathrm{~mm} \times 1.66 \mathrm{~mm}$.) (b) Axial strain contour map just prior to failure. (The field of view is $3.8 \mathrm{~mm} \times 1.66 \mathrm{~mm}$.)

shear behavior of the weld materials, including the types SA12, SB6, SB12, SC3, SC6, and SC12. Table 2b lists three simple shear coupons tested in this work that failed in the gage section through the shearing mode. The remaining shear coupons did

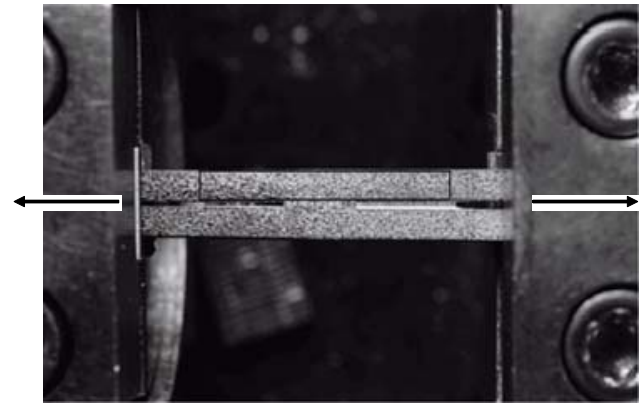

(a) Force right before failure: $730.8 \mathrm{~N}$. The blue DIC box dimensions are $15.77 \mathrm{~mm} \times 1.728 \mathrm{~mm}$.

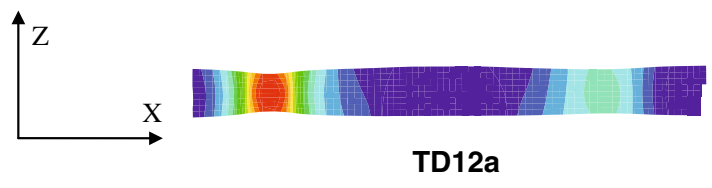

(b) The field of view is $15.77 \mathrm{~mm} \times 1.728 \mathrm{~mm}$.

Fig. 11 (a) Digital image of tensile coupon TD12b (GMT\#181). Blue box shows digital grid region used for DIC. The arrows denote the tensile axis. (Force right before failure: $730.8 \mathrm{~N}$. The blue DIC box dimensions are $15.77 \mathrm{~mm} \times 1.728 \mathrm{~mm}$.) (b) Axial strain contour map just prior to failure. (The field of view is $15.77 \mathrm{~mm} \times 1.728$ $\mathrm{mm}$.

not fail in shear, but rather, failed via fracture outside the joint region. This is shown in the digital image of Fig. 15 for simple shear coupon SC3a where the weld region remained intact, and failure occurred in the base metal regions of the two sheets upon significant bending (a double-lap shear test coupon based on the spot welded three steel sheets could be used to avoid the bending problem in a subsequent study). These shear coupons did not provide any explicit information about the shear strength of the weld metals, and will not be discussed further.

However, simple shear test coupons SA12a, SA12b, and SC6a, as detailed in Figs. 16, 17, and 18, respectively, did fail in shear (i.e., the material broke along the shear plane parallel to the horizontal loading axis). Note that the rounded notches in the digital images resulted from additional EDM processing to shorten the weld region (in trial tests using the long gage section of the entire spot welds, fracture of the gage section never occurred). Figure 16(c) shows strain contours in the weld region of Fig. 16(a) just prior to failure, with the peak shear strain being $12.1 \%$ (red contour patches). Note that strains are concentrated parallel to the joined sheet surfaces within the weld region, and fracture occurred on the left side of the weld relative to the digital image in Fig. 16(a). A digital image of the shear coupon just after fracture is shown in Fig. 16(b). The shear stress-shear strain curve for SA12a in Fig. 16(d) suggests that the yield strength in shear $(194 \mathrm{MPa})$ was far below $1 / \sqrt{3}$ times the yield strength of $1196 \mathrm{MPa}$ in uniaxial tension (Ref 3) (assuming the von Mises yield criterion). Some insight into this problem was provided by the SEM images of the ruptured surface shown in Fig. 16(e) and 16(f). Material defects (similar to those in Fig. 5d) suggest nonductile failure. As shown in Fig. 17, coupon SA12b produced results (i.e., shear strain field characteristics (Fig. 17c), shear stress level (Fig. 17d), and ruptured surface defects (Fig. 17e and 17f)) very similar to those of coupon SA12a, although the final strain level is higher. 


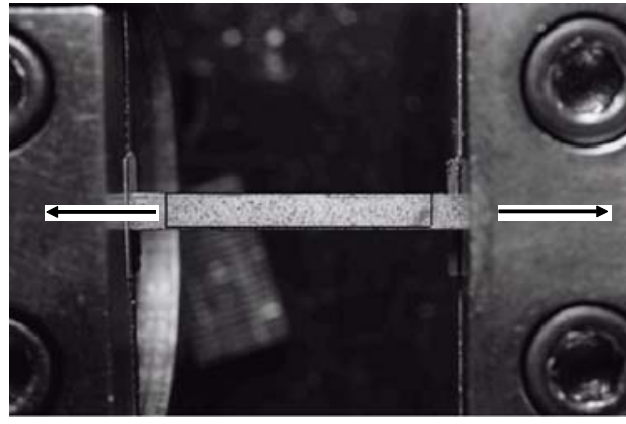

(a) Force right before failure: $500.68 \mathrm{~N}$. The blue DIC box dimensions are $15.3 \mathrm{~mm} \times 1.89 \mathrm{~mm}$

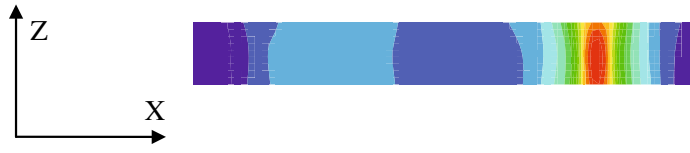

TE12b

(b) The field of view is $15.3 \mathrm{mmx} 1.89 \mathrm{~mm}$.

Fig. 12 (a) Digital image of tensile coupon TE12b (GMT\#182). Blue box shows digital grid region used for DIC. The arrows denote the tensile axis. Force right before failure: $500.68 \mathrm{~N}$. The blue DIC box dimensions are $15.3 \mathrm{~mm} \times 1.89 \mathrm{~mm}$.) (b) Axial strain contour map just prior to failure. (The field of view is $15.3 \mathrm{~mm} \times 1.89 \mathrm{~mm}$.)

The signs in shear strain are different for coupons SA12a and $\mathrm{SA} 12 \mathrm{~b}$ due to the different lap-shear loading conditions (see Figs. $16 \mathrm{~b}$ and $17 \mathrm{~b})$.

Coupon SC6a also failed in shear. The true shear stress-true shear strain curve (Fig. 18d) indicates that the yield strength in shear was about $350 \mathrm{MPa}$, which was again far below $1 / \sqrt{3}$ of the $1196 \mathrm{MPa}$ yield strength in uniaxial tension. In addition, a peak shear strain of only $0.7 \%$ was achieved, which is nearly an order-of-magnitude lower than the $6.6 \%$ shear strain noted in Fig. 16(d) for coupon SA12a. On the one hand, the SEM images of the ruptured surface (Fig. 18e and 18f) did not reveal any microstructural abnormalities comparable to those for test coupon SA12a (see Fig. 16f). The surface was very much featureless leading us to conclude that the rupture was less ductile. On the other hand, the shear strain map showed that the shear strain was localized only at the edge of the gage section (see Fig. 18c, contour levels on the right side of the map). Hence, the discrepancy between the yield strength in shear and $1 / \sqrt{3}$ of the yield strength in uniaxial tension is likely due to premature edge cracking (Fig. 18c). This was observed in a small number of all-weld miniature test coupons in (Ref 3 ).

\section{Finite Element Analysis of Tension Tests}

\subsection{Finite Element Models}

Tensile test coupon TA12a was modeled with the commercial (implicit) finite element (FE) program ABAQUS6.5 (HKS, Inc., Providence, RI). The FE analysis assumed an isotropic elastic-plastic von Mises material model obtained from the uniaxial tensile tests on the homogeneous miniature coupons of DP600 base, HAZ, and fusion materials reported

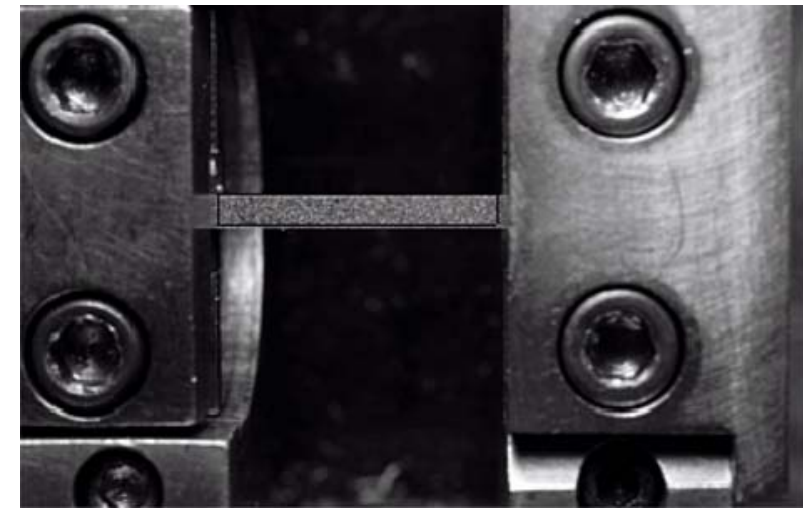

(a) Force right before failure: $142.97 \mathrm{~N}$. The blue DIC box dimensions are $16.35 \mathrm{~mm} \times 1.74 \mathrm{~mm}$.

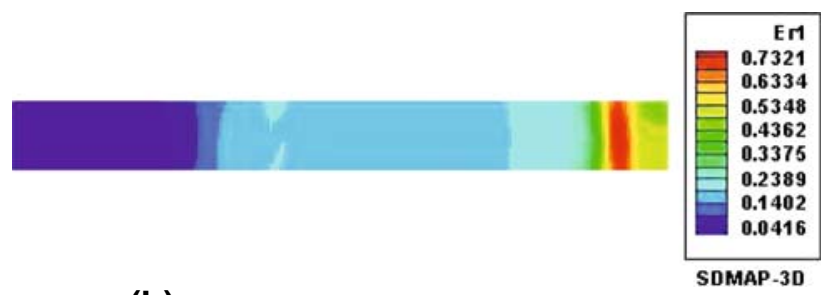

(b) The field of view is $16.35 \mathrm{~mm} \times 1.74 \mathrm{~mm}$.

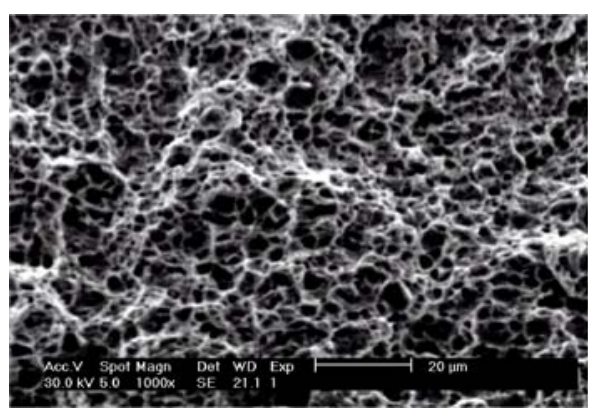

(c) $1000 x$

Fig. 13 (a) Digital image of tensile coupon TF12b (GMT\#177). Blue box shows digital grid region used for DIC. The arrows denote the tensile axis. (Force right before failure: $142.97 \mathrm{~N}$. The blue DIC box dimensions are $16.35 \mathrm{~mm} \times 1.74 \mathrm{~mm}$ ) (b) Axial strain contour map just prior to failure (The field of view is $16.35 \mathrm{~mm} \times 1.74 \mathrm{~mm}$.). (c) SEM image of one fracture surface showing microstructural features $(1000 \times)$

in (Ref 3). For all simulations, the Young's modulus was $E=210 \mathrm{GPa}$, and Poisson's ratio was $v=0.33$. The FE analysis was focused on the simulated material response curves for tensile coupon TA12a. The validity of the plastic stress-strain curves for base and FZ materials, and especially for the simulated HAZ material, is of special interest. As the HAZ material was difficult to investigate directly due to its small zone size and possible spatial variation of its properties in an actual spot weld, only simulated HAZ material was studied (see Ref 3 for more details). The HAZ material was generated through special simulating heat treatments and weld cycles, and both "soft" and "hard" HAZ materials (with "hard" pertaining to a high hardness and ultimate tensile strength) resulted. One of our ultimate objectives was to optimize the variation of the plastic stress-strain response within the HAZ using the best fit between the experimentally 


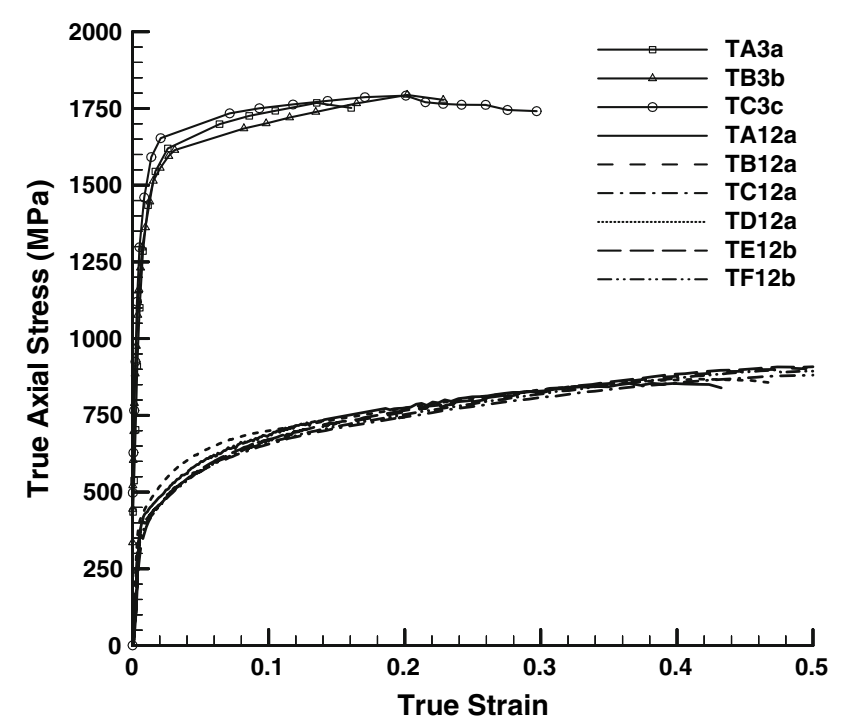

Fig. 14 Local axial true stress-true strain curves of various tensile joint coupons using the strain measure that is defined by Eq. A3

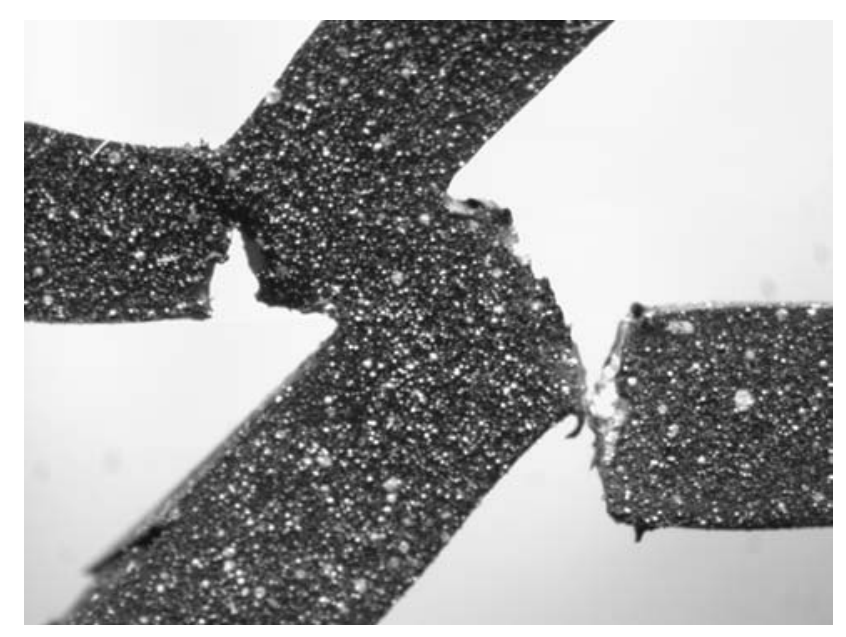

Fig. 15 Shear test coupon SC3a (GMT\#90): failure in bending rather than in shear. The field of view of the entire image is $7.3 \mathrm{~mm} \times$ $5.5 \mathrm{~mm}$

measured material response and the FE-predicted material response of tension coupons.

The plastic stress-strain curves for the various material zones are shown in Fig. 19, and were extracted according to the procedures described in (Ref 3, 13). The dashed lines in Fig. 19 were extrapolated for the purpose of fracture analysis in (Ref 13) and only the solid line portion (up to a strain of $65-70 \%$, as measured via experiment) of each curve was used in the simulations in this study. As the deformation of the FZ was found to be very minimal $(<1 \%)$ according to the strain distribution map of coupon TA12a (Fig. 8a), the two uppermost true stress-true strain curves for the FZ and HAZ materials, as shown in Fig. 19 were adequate for the FE simulations (i.e., no extrapolation of these curves beyond the strain of $15 \%$ was needed due to the small strains accumulated in these two materials in this study). The plastic stress-strain curves for the base and the soft HAZ materials, taken from GMT\#92 and
GMT\#77 in (Ref 3), respectively, exactly reproduced the stressstrain curves resulting from the strain averaged within the entire gage section (Eq A1), the strain averaged within the necked portion of the gage section (Eq A2), and the strain averaged along the centerline of the gage section (Eq A3). For the FZ and the hard HAZs (GMT\#80 and GMT\#76 in Ref 3), the experimental stress strain curves were exactly reproduced up to a strain of $15 \%$.

The material zone designation for the FE model of tensile coupon TA12a is shown in Fig. 20(a) (noting that we use $1=x$, $2=y$, and $3=z$ interchangeably throughout this article), and the salient geometric details observed along the "2-direction," which is the camera view, are shown in Fig. 20(b). Figure 20(c) shows additional dimensions relative to the fusion, HAZ, and base material zones from a view looking along the "3-direction" relative to the coordinate axes in Fig. 20(a). The thickness of the FZ at the center of the gage section is assumed to be $0.56 \mathrm{~mm}$. According to the digital image and data record of tensile test TA12a, the length of the FZ component of the gage section was estimated at $7.4 \mathrm{~mm}$. Based on the hardness profile across the different material zones and microstructural examination (Ref 3), the thickness of the HAZ was estimated to be $0.99 \mathrm{~mm}$. The gripper region was $10 \mathrm{~mm}$ with a corresponding thickness of $2 \mathrm{~mm}$. As a slightly nonsymmetric strain pattern about the centerline of the FZ was observed to develop over the gage section in the experiments (due to both the somewhat nonsymmetric geometry of the test coupon and boundary gripping conditions), the gage section (12 mm length) in the FE model was accordingly made nonsymmetric as well by trial and error so the resulting strain pattern about the centerline of the FZ was similar to that observed in the experiments. The maximum resulting change in the test coupon geometry was less than $1 \%$ of the coupon width.

The boundary conditions applied in the finite element model are shown in Fig. 21. Boundary nodes at the left end of the coupon were fixed (i.e., six degrees of freedom, viz., three axial displacements and three rotations). This simulates the fixed end of the tensile coupon in the tensile stage (see Fig. 4). A displacement-controlled loading condition was imposed on the right end (note red arrows imposing the same axial displacements along the 1-direction at each boundary node in Fig. 21). This simulates the moving end of the tensile coupon in Fig. 4. The FE mesh, shown in Fig. 22, consisted of 1458 elements. Three-dimensional solid elements with 20 nodes (C3D20) were used in the FE model. The smallest mesh dimension was $0.165 \mathrm{~mm}$ in the axial loading direction. This was adequate for modeling diffuse necking up to an average strain of 0.5-0.6 (Ref 13).

\subsection{Numerical Simulations and Results}

Various material combinations were utilized to simulate the HAZ material: these are listed in Table 3. To make a direct comparison between simulation and experiments, the material response curves were calculated exactly in the same way as in the experiment. That is, the local material response curves were calculated where the true surface strain was averaged within an area of $0.4 \times 0.4 \mathrm{~mm}^{2}$ across the coupon width, the same physical dimension of the subset size and digital strain gage size in the image correlation analysis of the experimental data. Simulation "a" involved a two-material system, as indicated in Table 3. In this simulation, the FZ material was 


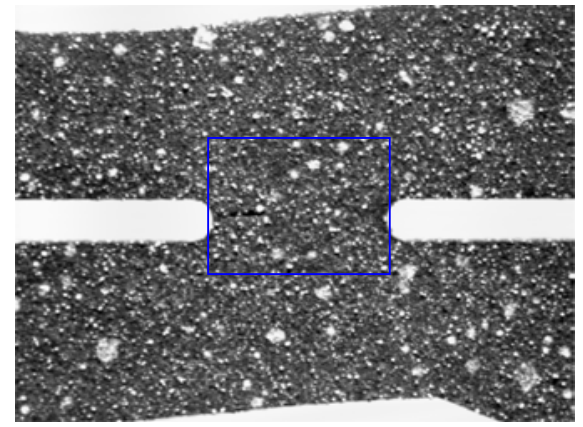

(a) The field of view of the entire image is $4.4 \mathrm{~mm} \times 3.3 \mathrm{~mm}$.
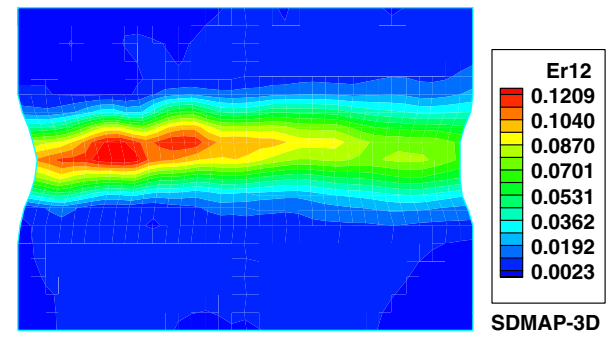

$\varphi_{z}$

$\stackrel{\mathrm{x}}{\longrightarrow}$ (c) The DIC region of interest is $1.3 \mathrm{~mm} \times 1.0 \mathrm{~mm}$

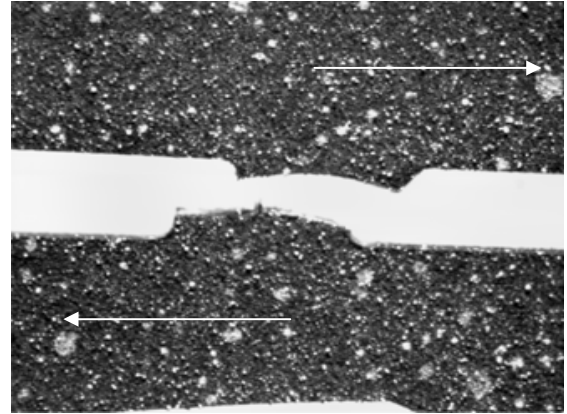

(b) The field of view of the entire image is $4.4 \mathrm{~mm} \times 3.3 \mathrm{~mm}$.
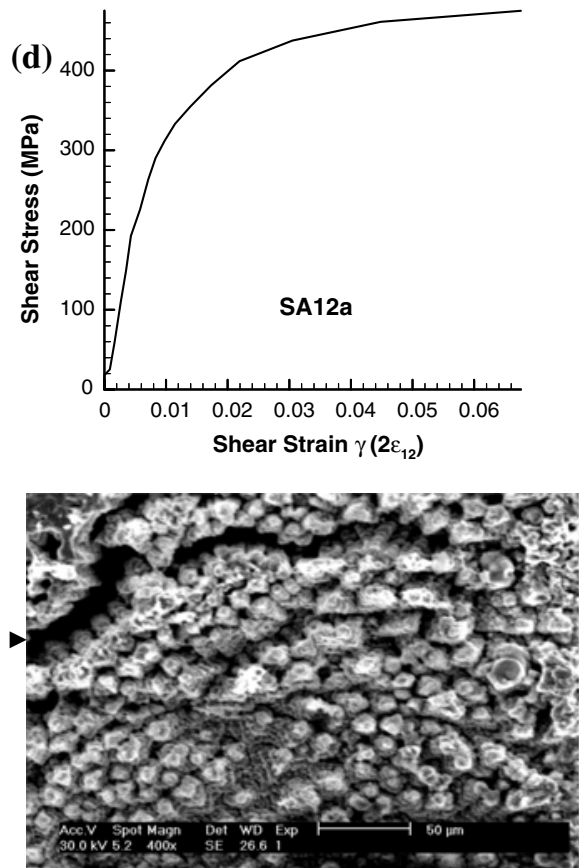

(f) $400 \mathrm{X}$

Fig. 16 Shear test SA12a (GMT\#145): (a) digital image before loading (The field of view of the entire image is $4.4 \mathrm{~mm} \times 3.3 \mathrm{~mm}$.); (b) after failure (The field of view of the entire image is $4.4 \mathrm{~mm} \times 3.3 \mathrm{~mm}$.); (c) shear strain contours (The DIC region of interest is $1.3 \mathrm{~mm} \times 1.0 \mathrm{~mm}$ ); (d) true shear stress-true shear strain curve; (e) SEM image of the fracture surface (43×); (f) material defects at higher magnification, dashed line connects the same defect region in the two images $(400 \times)$

assigned both to FZ and HAZ. So the gage section only contained two kinds of materials: base metal and FZ material. As shown in Fig. 23 the predicted true stress-true strain curve \#1 of TA12a falls between the experimental curves of TA12a and the base metal BM. The initial part of the predicted curve follows the base metal curve, as reported in (Ref 3). In simulation "b," the HAZ (0.99 mm long) was assumed to contain $1 / 3(0.33 \mathrm{~mm})$ of hard HAZ material (the simulated hard HAZ GMT\#76 (Ref 3)) next to the FZ, and 2/3 $(0.66 \mathrm{~mm})$ of the soft HAZ material (the simulated soft HAZ GMT\#77 (Ref 3)); their true stress-true strain curves are shown in Fig. 19. The predicted true stress-true strain curve "b" (Fig. 23) falls between the predicted true stress-true strain curve "a" and the experimental base metal (BM) curve (solid curve in Fig. 23). But the initial part of the predicted curve still follows the base metal. In simulation "c," the material flow stress at a fixed true strain inside the HAZ was assumed to vary linearly from one end (base metal) to the other end (FZ).

Figure 23 shows that the predicted local true stress-true strain curves "a," "b," and "c" are only slightly sensitive to material variation (described by the models in Table 3 ) in the HAZ. The predicted true stress-true strain curves (the solid symbols in Fig. 23) falls between the base metal coupon BM (Ref 3 ) and TA12a within the true strain of $40 \%$. Note that each material model in Table 3 provides what can be considered a lower bound on the experimentally measured true stress-true strain curve, in that they lead to computed true stress-true strain curves that closely match the actual base metal curve up to $40 \%$ strain. Differences of these predicted curves with the experimental curve for TA $12 \mathrm{a}$ are within $3-4 \%$ strain at the same stress. At strains in excess of $40 \%$ however, the overall trend of the curves from " $a$ " and "c" run closer to the experimental BM curve, although the flow stresses in both of them are higher than 


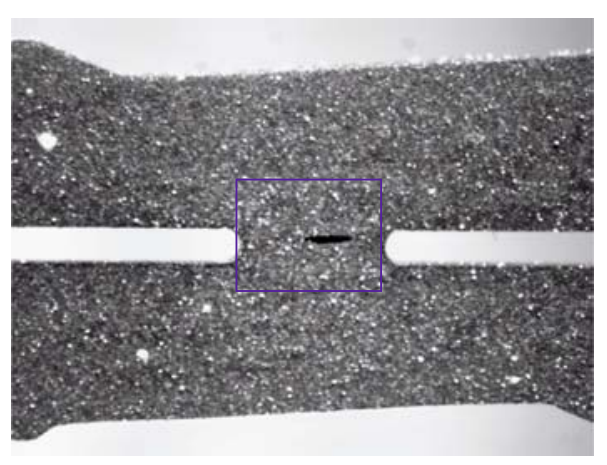

(a) The field of view of the entire image is $5.2 \mathrm{~mm} \times 3.9 \mathrm{~mm}$.
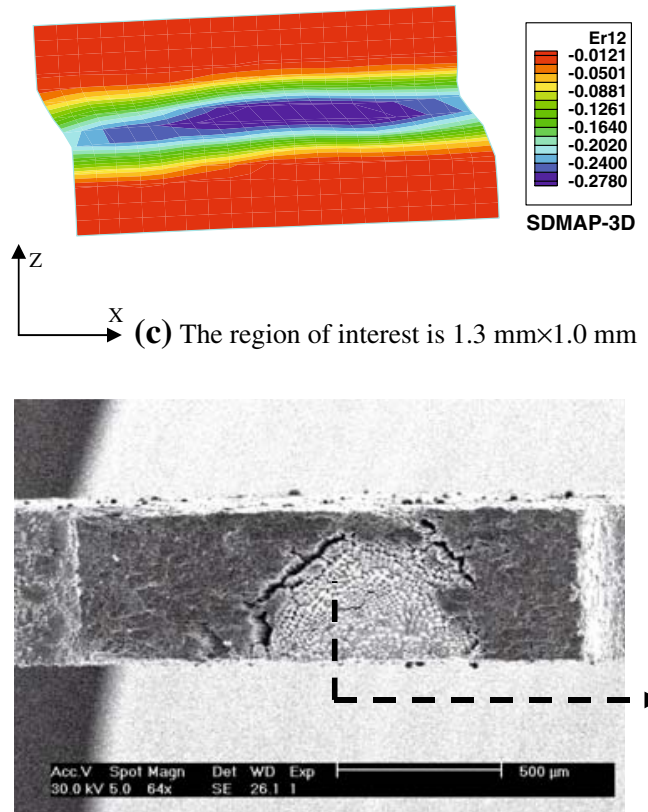

(e) $64 \mathrm{X}$

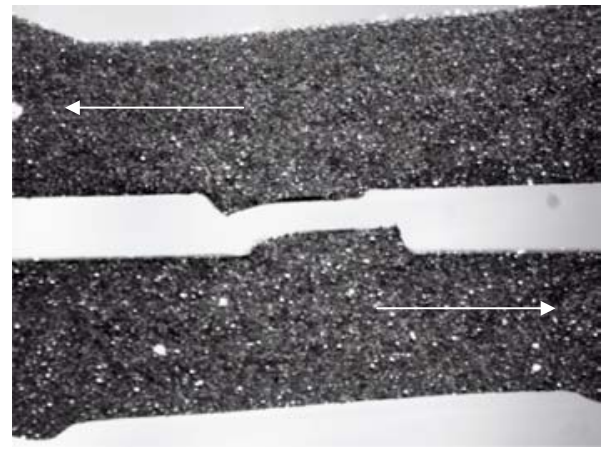

(b) The field of view of the entire image is $5.2 \mathrm{~mm} \times 3.9 \mathrm{~mm}$.
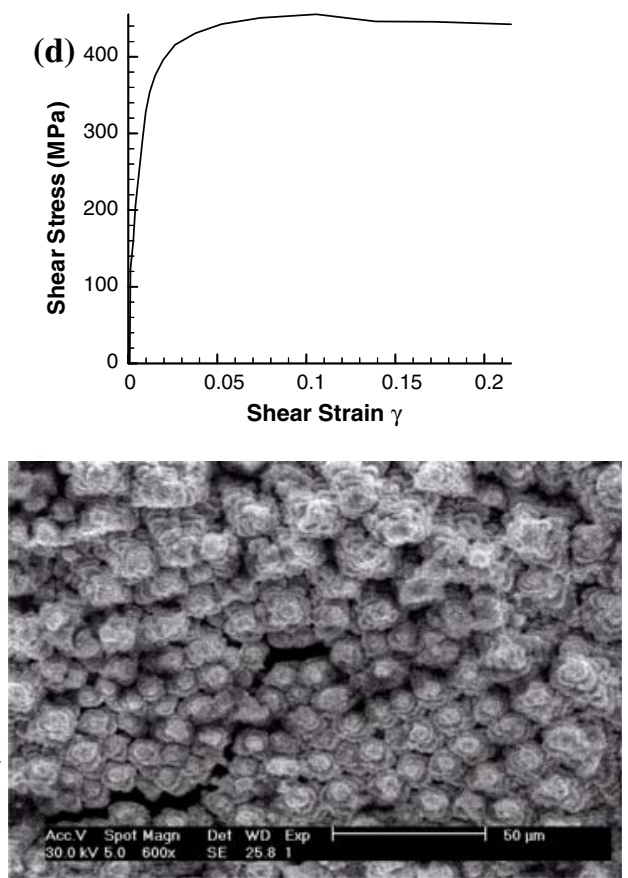

(f) $600 \mathrm{X}$

Fig. 17 Shear test SA12b (GMT\#151): (a) digital image before loading with blue DIC box: dark, lenticular patch is part of the contrast pattern, not a defect (The field of view of the entire image is $5.2 \mathrm{~mm} \times 3.9 \mathrm{~mm}$.); (b) after failure (The field of view of the entire image is $5.2 \mathrm{~mm} \times 3.9$ $\mathrm{mm}$.); (c) shear strain field (The region of interest is $1.3 \mathrm{~mm} \times 1.0 \mathrm{~mm}$ ); (d) shear stress-strain curve; (e) SEM image of the fracture surface at lower magnification; (f) material defects at higher magnification. The arrow between (e) and (f) shows identical regions

the experimental curves. One cause for such a discrepancy may be due to the limited spatial resolution of the DIC-based strain measurements inside the neck that could underestimate the strain and stress levels inside the neck.

\section{Conclusions}

Axial strain localization was observed in all resistance spot welded DP600 tensile coupons. The material responses of the coupons are dependent on their gage section length and gage section locations relative to the weld FZ. If the necked gage section is within the weld FZ, then the material response is very close to that of the homogeneous FZ material. If the necked gage section is outside the weld FZ and HAZ, then the coupon fails in the base material, and the material response of the entire weld is very close to that of the homogeneous base metal. Most of the resistance spot welded DPS joints are very resistant to shearing unless the weld FZ contains material defects. One coupon failed by shearing without significant material defects. We surmise that this shear failure is due to premature edge cracking (fracture) from an undetected defect, or set of defects.

The mechanical response of a single weld coupon in tension was analyzed with a simple FE model. For a fixed model geometry (40 mm total length, $12 \mathrm{~mm}$ gage length, $7.4 \mathrm{~mm}$ FZ, $0.99 \mathrm{~mm}$ HAZ on each side of the FZ, and $0.56 \mathrm{~mm}$ thickness in gage section), the predicted true stress-true strain curves of the joint coupon fall between the experimental true stress-true strain curve of TA12a and the base metal. The predicted true stress-true strain curve is only slightly sensitive to the material variation in the HAZ. The variation of the material composition in the HAZ only alters the predicted true 


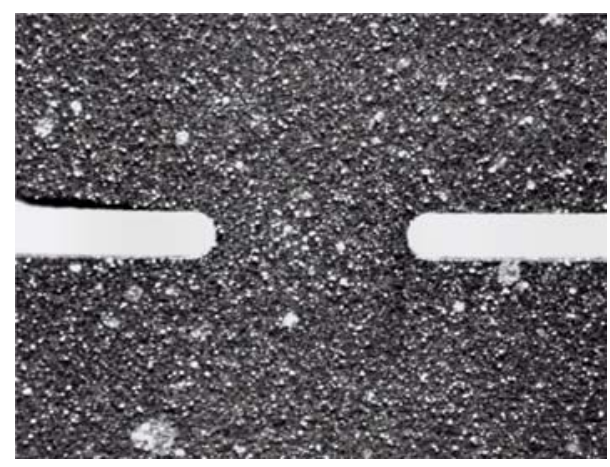

(a) The field of view of the entire image is $5.2 \mathrm{~mm} \times 3.9 \mathrm{~mm}$.
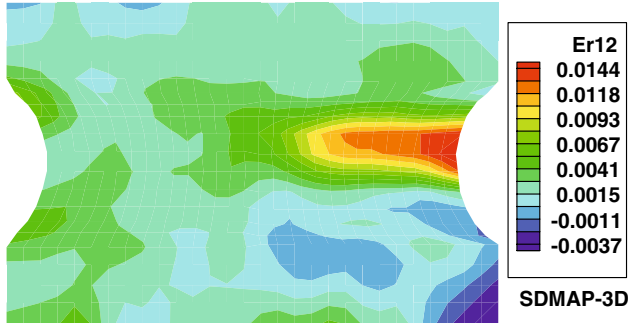

(c) The region of interest is $1.3 \mathrm{~mm} \times 1.0 \mathrm{~mm}$

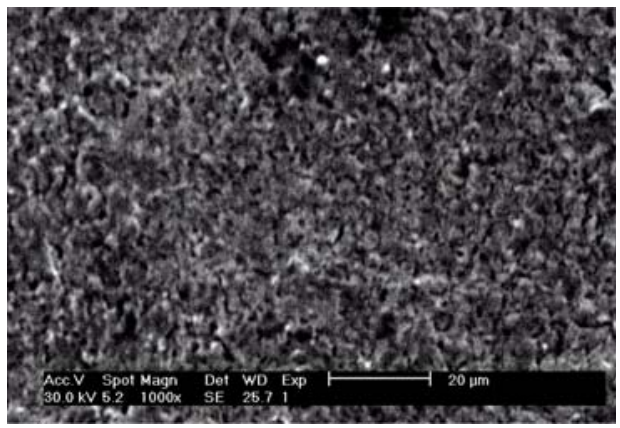

(e) $1000 \mathrm{X}$

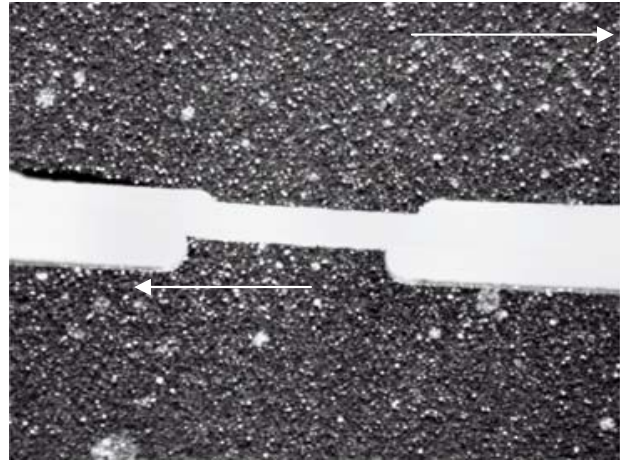

(b) The field of view of the entire image is $5.2 \mathrm{~mm} \times 3.9 \mathrm{~mm}$.
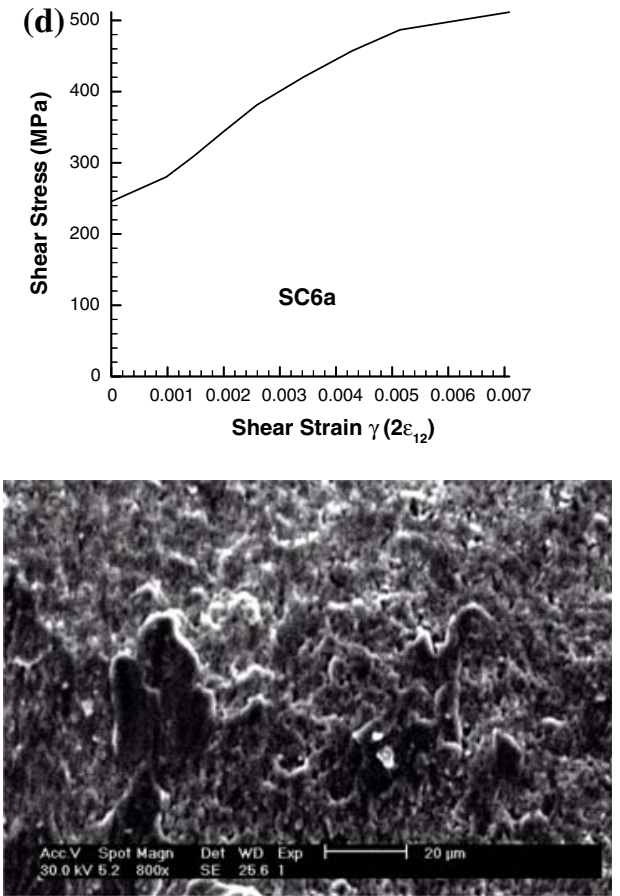

(f) $800 \mathrm{X}$

Fig. 18 Shear test SC6a (GMT\#143): (a) digital image before loading (The field of view of the entire image is $5.2 \mathrm{~mm} \times 3.9 \mathrm{~mm}$.); (b) after failure (The field of view of the entire image is $5.2 \mathrm{~mm} \times 3.9 \mathrm{~mm}$.); (c) shear strain field (The region of interest is $1.3 \mathrm{~mm} \times 1.0 \mathrm{~mm}$ ); (d) shear stress-strain curve; (e-f) SEM images of ruptured surface

stress-true strain curve after a strain of $10 \%$ and does not change the initial part of the curve (i.e., at strains less than $10 \%$ ). The initial part of the simulated true stress-true strain curve always follows the experimental true stress-true strain curve of the base metal. The work reported herein suggests that the material models from tensile test of coupons consisting entirely of one weld zone material (i.e., BM, HAZ, and fusion) can be used to simulate the deformation response of a entire spot weld in a finite element simulation to a reasonable degree of accuracy. An additional test of this observation might involve subjecting single welds to bending.

\section{Acknowledgments}

The authors are grateful to M. Marya for support with spot welding. Gary Jones and Tim Johnson of the GMR Engineering
Design group prepared drawings for each coupon, and Warren Cavanaugh of the Pre-Production Operations group cut all of the coupons from individual spot welds with wire EDM.

\section{Appendix}

Four definitions of the average axial true strain measures were employed in this study. The corresponding mathematical definitions of the average strain measures are as follows:

$\bar{\varepsilon}_{1}^{(1)}=\frac{1}{M N} \sum_{j=1}^{N} \sum_{i=1}^{M} \varepsilon_{1}(i, j)$,

where $\bar{\varepsilon}_{1}^{(1)}$ is the axial strain averaged over the entire gage section (following the conventional tensile test methodology), 


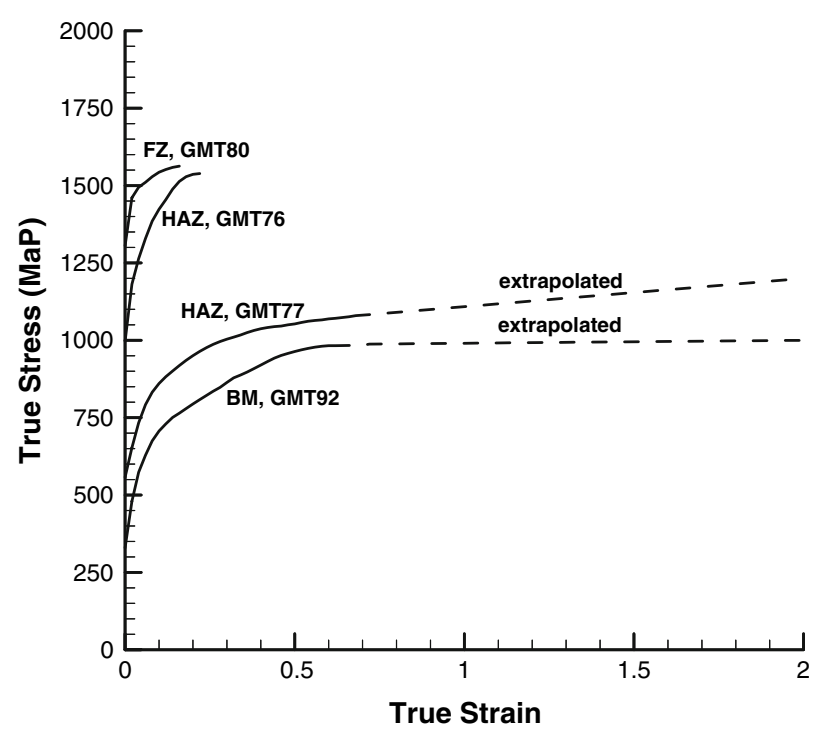

Fig. 19 Material models for different material zones extracted from previous experiments $(\operatorname{Ref} 3,13)$
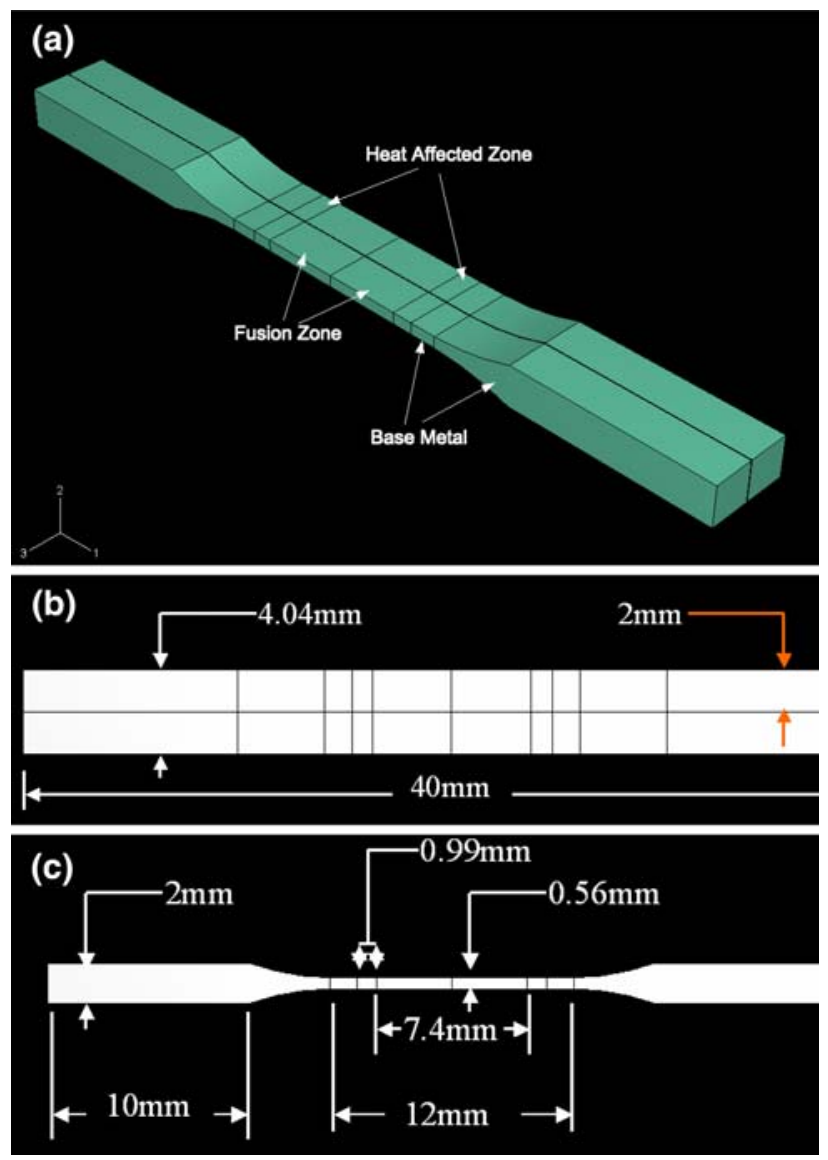

Fig. 20 (a) Finite element model geometry and material zone designation for spot-welded tensile bar. Camera view is normal to the curved portion of the gage section (with material zones labeled accordingly). (b) Camera view of the finite element model showing thickness and length dimensions. (c) Side view of FE model with additional dimensions

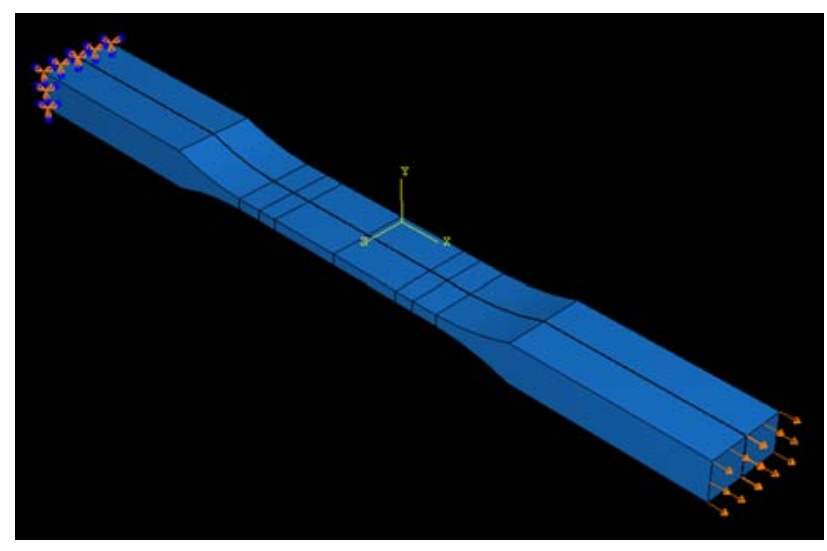

Fig. 21 Boundary conditions applied in FE model (note that we use $1=x, 2=y$, and $3=z$ interchangeably throughout here)

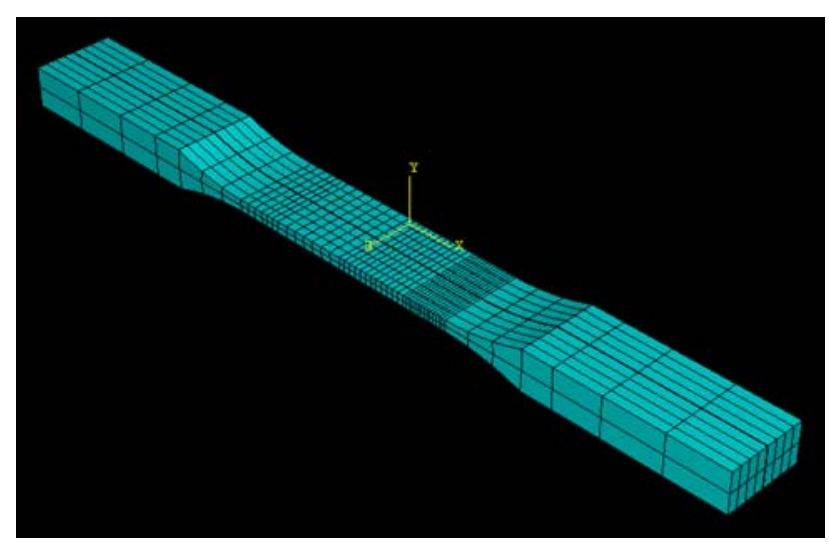

Fig. 22 Finite element mesh consisting of C3D20 solid elements

$M$ and $N$ are the total numbers of grid points along the gage length and width directions, respectively, and $\varepsilon_{1}(i, j)$ is the local axial strain at each grid point $(i, j)$ obtained via DIC;

$\bar{\varepsilon}_{1}^{(2)}=\frac{1}{M_{n} N} \sum_{j=1}^{N} \sum_{i=M_{1}}^{M_{1}+M_{n}} \varepsilon_{1}(i, j)$,

where $\bar{\varepsilon}_{1}^{(2)}$ is the axial strain averaged over the entire neck region (this is the lower bound estimate of average strain in the diffuse neck), $M_{1}$ and $M_{n}$ are the starting and total number of grid points along the gage length direction of the neck region, respectively;

$\bar{\varepsilon}_{1}^{(3)}=\frac{1}{N} \sum_{j=1}^{N} \varepsilon_{1}\left(M_{0}, j\right)$,

where $\bar{\varepsilon}_{1}^{(3)}$ is the axial strain averaged along the bar cross section with the smallest width (i.e., the neck center line at $I=M_{0}$ ), but not necessarily perfectly normal to the gage section;

$\bar{\varepsilon}_{1}^{(5)}=\varepsilon_{1}\left(M_{0}, N_{0}\right)=\max _{j=1, N}\left[\varepsilon_{1}\left(M_{0}, j\right)\right]$,

where $\bar{\varepsilon}_{1}^{(5)}$ is the maximum axial strain at the center of a diffuse neck corresponding to the grid point $\left(M_{0}, N_{0}\right)$. This 


\begin{tabular}{llll}
\hline & & \multicolumn{2}{c}{ The assignment of materials within each zone } \\
\cline { 2 - 4 } Simulation cases (Run number) & BM & HAZ & FZ \\
\hline a (34) & Base metal & Weld & Weld \\
b (35) & Base metal & Average (a) & Weld \\
c (39) & Base metal & Gradient (b) & Weld
\end{tabular}

(a) The true stress-strain curve of the HAZ material is assumed to be the average of the ones obtained from simulated soft (GMT\#77) and hard (GMT\#76) HAZ materials (see details in Ref. 3 as well as Fig. 20)

(b) The true stress-strain curve of the HAZ material is assumed to be linearly varying from that of the base metal to that of the weld metal across the HAZ dimension

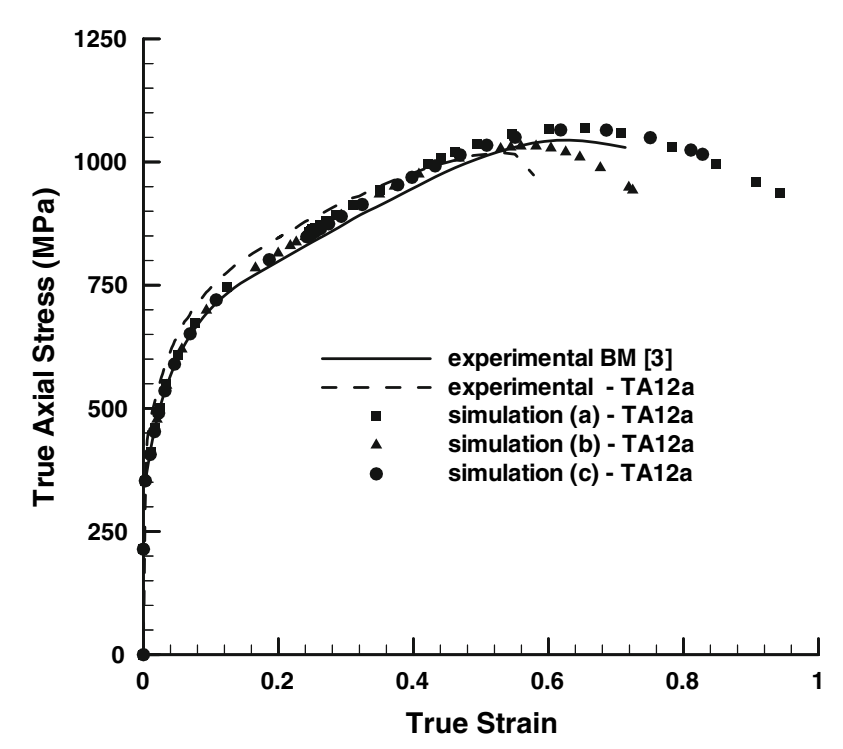

Fig. 23 Comparison of predicted and experimental true stress-true strain curves

definition of axial strain provides the upper bound estimate of measurable average strain in the diffuse neck. Since the entire gage section was used to compute $\bar{\varepsilon}_{1}^{(1)}$, local strain heterogeneities were averaged out over the gage section. Alternatively, the strain fields selected for computing $\bar{\varepsilon}_{1}^{(2)}$, $\bar{\varepsilon}_{1}^{(3)}$, and $\bar{\varepsilon}_{1}^{(5)}$, were measured over the entire neck region, or a selected part of the neck region, and hence local strain heterogeneities were more accurately quantified. Both analytical and numerical analyses have shown that the average axial true strains $\bar{\varepsilon}_{1}^{(2)}$ and $\bar{\varepsilon}_{1}^{(3)}$, as defined, respectively, by Eq A2 and $\mathrm{A} 3$, are the most accurate estimates of uniaxial true strain and true stress (via Eq 1) beyond diffuse necking in various tensile bar geometries (Ref 13). The definitions $\bar{\varepsilon}_{1}^{(1)}$ and $\bar{\varepsilon}_{1}^{(5)}$ provide uniaxial true stress-strain curves that bound the actual uniaxial true stress-strain curve irrespective of tensile bar geometry.

\section{References}

1. D.T. Llewellyn and D.J. Hillis, Review: Dual Phase Steel, Ironmaking and Steelmaking, 1996, 23(6), p 471

2. M. Marya, K. Wang, L.G. Hector Jr., and X.Q. Gayden, Tensile-Shear Forces and Fracture Modes in Single and Multiple Weld Specimens in Dual-Phase Steels, ASME J. Manuf. Sci. Eng., 2006, 128, p 287-298

3. W. Tong, H. Tao, X.Q. Jiang, N. Zhang, M.P. Marya, L.G. Hector Jr., and X.Q. Gayden, Deformation and Fracture of Miniature Tensile Bars with Resistance-Spot-Weld Microstructures, Metall. Mater. Trans., 2005, 36A, p 2651-2669

4. M. Marya and X.Q. Gayden, Development of Requirements for Resistance Spot Welding Dual-Phase (DP600) Steels, Part I: The Causes of Interfacial Fracture, General Motors R\&D Center Technical Report No. 9885, 2004, Warren, MI

5. W. Tong, An Evaluation of Digital Image Correlation Criteria for Strain Mapping Applications, Strain, 2005, 41(4), p 167-175

6. B.W. Smith, X. Li, and W. Tong, Error Assessment of Strain Mapping by Digital Image Correlation, Exp. Tech., 1998, 22(4), p 19-21

7. W. Tong, Detection of Plastic Deformation Patterns in a Binary Aluminum Alloy, Exp. Mech., 1997, 37(4), p 452-459

8. W. Tong, Strain Characterization of Propagative Deformation Bands, J. Mech. Phys. Solids, 1998, 46(10), p 2087-2102

9. W. Tong, An Adaptive Backward Image Correlation Technique for Deformation Mapping of a Growing Crack in Thin Sheets, Exp. Tech., 2004, 28(3), p 63-67

10. N. Zhang and W. Tong, An Experimental Study on Grain Deformation and Interactions in a Binary Aluminum Alloy, Int. J. Plasticity, 2004, 20, p 523-542

11. W. Tong and H. Tao, Crack Tip Fields and Fracture Behavior in a NiTi Shape Memory Alloy Thin Sheet, Mater. Res. Soc. Symp. Proc., 2004, 785, p D771-D776

12. W. Tong, H. Tao, N. Zhang, and L.G. Hector, Time-Resolved Strain Mapping Measurements of Individual Portevin-Le Chatelier Deformation Bands, Scripta Mater., 2005, 53(1), p 87-92

13. H. Tao, "Plastic Deformation and Fracture Behaviors of Resistance Spot-Welded Dual-Phase Steel and Laser-Welded Aluminum Sheet Metals." Ph.D. Thesis, Department of Mechanical Engineering, Yale University, New Haven, Connecticut, 2006

14. M. Marya, L.G. Hector, R. Verma, and W. Tong, Microstructural Effects of AZ31 Magnesium Alloy on its Tensile Deformation and Failure Behaviors, Mater. Sci. Eng., 2006, A418, p 341-356

15. W. Tong, L.G. Hector, Jr., C. Dasch, H. Tao, and X. Jiang, Local Plastic Deformation and Failure Behavior of ND:YAG Laser Welded AA5182-O and AA6111-T4 Aluminum Sheet Metals, Met. Mater. Trans. $A$ (in press) 